AMBOS, KAI. "El derecho penal internacional en la encrucijada: de la imposición ad hoc a un sistema universal basado en un tratado internacional".

Polit. crim. Vol. 5, № 9 (Julio 2010), Art. 6, pp. 237-256.

[http://www.politicacriminal.cl/Vol_05/n_09/Vol5N9A6.pdf]

\title{
EI derecho penal internacional en la encrucijada: de la imposición ad hoc a un sistema universal basado en un tratado internacional
}

\author{
Dr. Kai Ambos * \\ kambos@gwdg.de
}

\section{Resumen}

El presente artículo pretende hacer un tour d'horizon desde la imposición (vertical) del sistema ad hoc de la justicia penal internacional al régimen universal (horizontal) de la Corte Penal Internacional. El objetivo es demostrar que hay varias cuestiones sin resolver y una creciente necesidad de mayor reflexión e investigación. Sin embargo, con este texto no se aspira a dar respuestas definitivas a las acuciantes cuestiones legales en él discutidas, sino que la intención es en primer lugar identificarlas y crear un necesario estado de alerta. En cualquier caso parece claro que la crisis de identidad del derecho penal internacional, tan lamentada por algunos académicos, sólo puede ser resuelta si el derecho penal internacional se establece como una disciplina por propio derecho y sobre la base de los principios fundamentales del derecho penal, inherentes a cualquier sistema legal justo y liberal.

\section{Palabras clave}

Derecho penal internacional, Tribunales Ad Hoc, Corte Penal Internacional, principio de tabula rasa, coautoría, autoría mediata, preparación de testigos

\begin{abstract}
The paper attempts to do a tour d'horizon from the (vertical) imposition of the ad hoc-system of international criminal justice to the (horizontal) universality of the ICC regime. It will show that there are many unresolved questions and an increasing need for further reflection and research. It does not pretend, however, to give any definite answers to the pressing legal issues discussed, but rather tries to identify them and create the necessary awareness in the first place. In any case, it seems clear that the identity crisis of International Criminal Law, criticized in some quarters, can only be overcome if ICL will be established as a discipline in its own right and on the basis of the fundamental principles of criminal law inherent to any liberal and fair criminal law system.
\end{abstract}

\section{Key words}

International Criminal Law, Ad Hoc Tribunals, International Criminal Court, tabula rasa principle, co-perpetration, indirect perpetration, witness proofing

\section{Los tribunales ad hoc: imposición ex post facto ad hoc.}

La era de los tribunales ad hoc terminó. Para la mayoría de nosotros esta es una buena noticia. La justicia penal internacional ad hoc siempre se caracterizó, con diferentes grados, por la violación de un principio general de derecho, a saber el principio nullum crimen sine lege. ${ }^{1}$ Si bien uno podría discutir la interpretación correcta -ya sea estricta o liberal- de este principio, su existencia

\footnotetext{
* Catedrático en Derecho Penal, Procesal Penal, Derecho Comparado y Derecho Penal Internacional en la Universidad Georg August de Göttingen: Juez del Tribunal Estadual (Landgericht) de Göttingen. Este trabajo es una versión ampliada y actualizada de la Conferencia realizada en la Marie Curie Network Conference "International Criminal Law: Present and Future Perspectives", Universidad de Leiden, Grotius Centre for International Legal Studies, The Hague, 15 de marzo de 2008. Fue publicado originalmente en inglés en STAHN C. / VAN DEN HERIK L. (eds.), Future perspectives on international criminal justice, The Hague: T.M.C. Asser Press, 2010 , pp. 161-177. Traducción del inglés realizada por Carolina Anello con asistencia de Natalia Luterstein (ambas Universidad de Buenos Aires).

1 Sobre sus orígenes véase AMBOS, Kai, "Nulla Poena Sine Lege in International Criminal Law", en HAVERMAN, R., OLUSANYA, O., (eds.), Sentencing and Sanctioning in Supranational Criminal Law (2006), pp. 17 a 21 (en castellano por ej. en Ciencias Penales, Costa Rica, no. 26, 2009, pp. 31-44).
} 
AMBOS, KAI. "El derecho penal internacional en la encrucijada: de la imposición ad hoc a un sistema universal basado en un tratado internacional".

como tal es indudable. De hecho, el Tribunal Militar Internacional de Nüremberg (TMI) lo reconoció como un principio (subjetivo) de justicia. ${ }^{2}$

La creación ex post facto de los tribunales ad hoc infringe ante todo el elemento temporal del principio nullum crimen, es decir, la prohibición de la retroactividad de las leyes penales. Todos los tribunales ad hoc -desde Nüremberg a La Haya, Arusha, Freetown, Pnom Penh, Bagdad y El Líbano (este último situado en La Haya) $-{ }^{3}$ fueron establecidos con posterioridad a la comisión de los crímenes que ellos mismos iban a juzgar. Si no se limitan a los crímenes del pasado puede haber un elemento de proyección hacia el futuro en su competencia, como es el caso del Tribunal Penal Internacional para la ex Yugoslavia (en adelante, TPIY) que "está habilitado para juzgar a los presuntos responsables de violaciones del derecho internacional humanitario cometidas a partir de 1991 en el territorio de la ex-Yugoslavia" (art. 1 Estatuto TPIY), es decir, hasta su cierre definitivo. No obstante, esto no modifica el carácter esencialmente retroactivo de este tipo de jurisdicción, al cual denominaré el defecto congénito de los tribunales ad hoc. Éste no puede ser eliminado por el recurso de estos tribunales a las fuentes no escritas del derecho internacional. Con esto no pretendo negar la existencia de actos que pueden ser reconocidos, más allá de toda duda razonable, como crímenes internacionales en el derecho internacional consuetudinario (parafraseando la famosa fórmula del Secretario General de la ONU en el Informe del TPIY) ${ }^{4}$ o que puedan considerarse "delictivos según los principios generales del derecho reconocidos por la comunidad internacional" (art. 15(2) Pacto Internacional de Derechos Civiles y Políticos (en adelante, PIDCP), también en el art. 7(2) del Convenio Europeo de Derechos Humanos (en adelante, $\mathrm{CEDH})$ ), pero en la práctica, estos estándares no se toman muy en serio una vez que un estatuto establece, con más o menos claridad, crímenes definidos. En realidad, es muy probable que la obligación de examinar la condición de derecho consuetudinario de los crímenes del Estatuto que surge, en principio, del carácter provisional de sus definiciones, ${ }^{5}$ se convierta en un mero enunciado teórico y que los jueces apliquen el Estatuto tal como está. ${ }^{6}$

Asimismo, mientras que la fórmula de los principios generales de los tratados de derechos humanos, debido a su alcance prácticamente ilimitado, constituye una violación flagrante de la seguridad jurídica (nullum crimen sine lege certa), una comprensión estricta de la costumbre, que requiera una opinio iuris no controvertida y una sólida práctica por parte de los Estados, ${ }^{7}$ podría constituir un fundamento legítimo de la existencia de crímenes no escritos. Por ejemplo, alguien podría alegar que los delitos cometidos por los Nazis contra los judíos y otros grupos

\footnotetext{
${ }^{2}$ Trial of the Major War Criminals before the International Military Tribunal ("The Blue Series"), Vol. XXII, p. 462: "In the first place, it is to be observed that the maxim nullum crimen sine lege is not a limitation of sovereignty, but is in general a principle of justice". Véase también KELSEN, Hans, "Will the Judgment in the Nuremberg Trial Constitute a Precedent in International Law?" (1947) 1 The International Law Quarterly 153, pp. 164-5 sosteniendo un enfoque subjetivo y denominando a la prohibición de normas ex post fact como un "principio de justicia", reimpreso en METTRAUX, G. (ed.), Perspectives on the Nuremberg trial (2008), p. 274.

${ }^{3}$ Sobre los diferentes tribunales ad hoc o tribunales mixtos, véanse AMBOS, Kai, OTHMANN, M. (eds.), New Approaches in International Criminal Justice: Kosovo, East Timor, Sierra Leone and Cambodia (2003); ROMANO, Romano (ed.), Internationalized Criminal Courts and Tribunals: Sierra Leone, East Timor, Kosovo and Cambodia (2004); SCHABAS, W., The UN International Criminal Tribunals: The Former Yugoslavia, Rwanda and Sierra Leone (2006); VON BRAUN, L., Internationalisierte Strafgerichte (2008); sobre Iraq y Líbano, SCHARF, M.P., "The Iraqi High Tribunal: A Viable Experiment in International Justice?" (2007) 5 JICJ, p. 258; COCKAYNE, J., (ed.), "Symposium: The Special Tribunal for Lebanon- A Cripple from Birth" (2007) 5 JICJ, pp. 1062-1174.

${ }^{4}$ Cfr. Informe presentado por el Secretario General de conformidad con el párrafo 2 de la Resolución 808 (1993) del Consejo de Seguridad, UN Doc. S/25704, 3 de mayo de 1993 y Corrigendum S/25704/Corr.1, 30 de Julio de 1993 (reimpreso en MORRIS, V., SCHARF, M.P., An Insider's Guide to The International Criminal Tribunal for The Former Yugoslavia, Vol. II (1995), pp. 3 y ss.), para. 34: "rules of international humanitarian law which are beyond any doubt part of customary law ..."

${ }^{5}$ Véase recientemente ZAHAR, A., SLUITER, G., International Criminal Law (2008), p. 80: "Their 'statutes' are retrospective and are not themselves law; they are, rather, pointers to a law existing in some form in the rarefied sphere of international law ...." Cfr. también: HOLLWEG, C. "Das Neue Internationale Tribunal der UNO und der Jugoslawienkonflikt", (1993) 48 Juristenzeitung 980, p. 985; AHLBRECHT, H., Geschichte der Völkerrechtlichen Strafgerichtsbarkeit im 20. Jahrhundert (1999), p. 244; HEINSCH, R., Die Weiterentwicklung des Humanitären Völkerrechts Durch die Strafgerichtshöfe für das Ehemalige Jugoslawien und Ruanda (2007), p. 65.

${ }^{6}$ Excepciones como el claro compromiso con el principio nullum crimen por Prosecutor v. Vasiljevic confirman la regla (Judgment, Case No. IT-98-32-T, 29 November 2002, párrafo 193): “A criminal conviction should indeed never be based upon a norm which an accused could not reasonably have been aware of at the time of the acts, and this norm must make it sufficiently clear what act or omission could engage his criminal responsibility".

${ }^{7}$ North Sea Continental Shelf Case (Germany v. Denmark), Judgment of 20 February 1969, [1969] ICJ Rep. 29, para. 74; Case Concerning Certain Paramilitary Activities In and Against Nicaragua (Nicaragua v. USA), Judgment of 27 June 1986, [1986] ICJ Rep. 79, para. 183. Véase también GRAF VITZTHUM, W., "Begriff, Geschichte und Quellen des Völkerrechts", en EL MISMO (ed.), Völkerrecht (2004), pp. 1 a 64, números marginales (mn.) pp. 1313; BROWNLIE, I., Principles of Public International Law (2003), pp. 4-6.
} 
disidentes habrían sido pasibles de ser legítimamente juzgados como crímenes de lesa humanidad, ya que ninguna persona razonable creería en la impunidad de esos actos a pesar de que no estaban codificados en el momento de su comisión. En cambio, la guerra de agresión Nazi, por muy ilegal que haya sido, no puede ser considerada un crimen internacional con un argumento de igual fuerza. El famoso Pacto "Briand-Kellogg" rechazó la célebre frase de Clausewitz de que "la guerra es una mera continuación de la política por otros medios", ${ }^{8}$ y sólo "condenó el recurso de la guerra como una solución de las controversias internacionales", y así de este modo se la prohibió "como un instrumento de política nacional", 9 es decir, claramente no criminalizó el uso de la fuerza. El Acuerdo de Londres ignoró esta sutil pero importante diferencia y dispuso de manera autoritaria que "planear, preparar, iniciar o hacer una guerra de agresión" es un crimen contra la paz. ${ }^{10}$ Incluso el Tribunal Militar Internacional (en adelante, TMI), con ese fundamento, consideró la guerra de agresión "no sólo como un crimen internacional" sino también como "el máximo crimen internacional" conteniendo "en sí mismo toda la maldad acumulada". ${ }^{11}$ Sin embargo, convertir sin más una mera prohibición en un delito significa ignorar, a nivel internacional, la diferencia fundamental entre la responsabilidad objetiva del Estado y la responsabilidad penal individual ${ }^{12} \mathrm{y}$, en el ámbito interno, la diferencia entre las prohibiciones administrativas sin carácter penal y los delitos. ${ }^{13}$ Esta suave transformación de una mera prohibición en delito sólo puede ser conciliada con la prohibición de retroactividad (nullum crimen sine lege praevia) si ésta es considerada como una regla con excepciones, justificando en este caso la excepción con la evidente ilegalidad que revestía la conducta en cuestión en el momento de la comisión, y teniendo en cuenta consideraciones de justicia. $^{14}$

En cualquier caso, de estas consideraciones se desprende claramente que el recurso al derecho penal no escrito está plagado de incertidumbres y dificultades que hacen a menudo prácticamente imposible encontrar un consenso sobre la criminalidad de una conducta particular. Por lo tanto, debería ser indiscutible que la calificación de una conducta como crimen por medio de una codificación conduce a una mayor claridad y seguridad. De hecho, esta es la razón por la cual las modernas jurisdicciones del common law han prácticamente derogado los crímenes del common

\footnotetext{
${ }^{8}$ VON CLAUSEWITZ, C., Vom Kriege, Vol. 1 (1832), para. 24 (en GRAHAM, J.J. (trad.), On War (1873)), ambos disponibles en: http://www.clausewitz.com/CWZHOME/VomKriege/VKTOC2.htm

9 Cfr. el art. 1 del Tratado de Renuncia a la Guerra (Pacto Briand - Kellog) como un Instrumento de Política Nacional, de 1928 (General Treaty for the Renunciation of War as an Instrument of National Policy), Sociedad de Naciones, Treaty Series, XCIV No. 2137 (1929), reimpreso en MC DONALD, G.K., SWAAK GOLDMAN O., (eds.), International Criminal Law, Vol. II, Part 1 (2000), pp. 57-8.

${ }^{10}$ Cfr. el art. 6 (a) del Estatuto TMI de 1945 (Acuerdo de Londres), 82 UNTS 280 (1951).

${ }^{11}$ Cfr. Trial of the Major War Criminals before the International Military Tribunal ("The Blue Series"), Vol. I p. 186; conc. US v. von Leeb, Trials of War Criminals before the Nuernberg Military Tribunals under Control Council Law No. 10 ("The Green Series", en adelante TWC por sus siglas en inglés), Vol. XI, 462, p. 472; US v. von Weizsäcker et al., TWC, Vol. XIV, 308, pp. 318 y ss.

12 Este tema ha sido abordado por JAHREISS, H., Der Bruch des Zwischenstaatlichen Friedens und Seine Strafbarkeit. Plädoyer vor dem Internationalen Militärgerichtshof zu Nürnberg (1946), p. 44 ("Wenn aber das deutsche Reich im Einzelfall entgegen einem noch gueltigen Nicht-Angriffs-Vertrag zum Angriff geschritten sein sollte, so hat es ein voelkerrechtliches Delikt begangen und haftet dafuer nach den Regeln des Voelkerrechts ueber voelkerrechtliche Delikte. Aber nur das Reich. Nicht der Einzelne, und waere e[r] das Staatsoberhaupt"). En el mismo sentido LATEMSER, H., "Looking Back at the Nuremberg Trials with Special Consideration of the Process Against Military Leaders", (1986) 8 Whittier Law Review 557, p. 572 (reimpreso en METTRAUX, Perspectives, cit. nota $\left.\mathrm{n}^{\circ} 2, \mathrm{p} .473\right)$.

${ }^{13}$ La diferencia también ha sido enfatizada por académicos norteamericanos con respecto al Pacto Briand Kellog, véase MCINTYRE, D. G., "The Nurernberg Trials" (1962) 24 Pittsburgh Law Journal 73, pp. 97 y ss., refiriéndose por un lado, a la Conferencia de la Asociación de Derecho Internacional de 1934 en la que "[N]ot one of the jurists suggested that the Pact authorized penal sanctions ..." (pp. 97-98); y por el otro, argumentando que el Senado de Estados Unidos de Norteamérica efectivamente no habría ratificado un tratado en donde se expusiera a los combatientes y jefes norteamericanos a una potencial responsabilidad internacional (pp. 98-99). También véase HARRIS, W.R., "International Human Rights and the Nuremberg Judgement" (1972) 12 Santa Clara Lawyer 209, pp. 216-17 para una ampliación sobre del Pacto Briand-Kellog; crít. también LIPPMAN, M., "Nuremberg: Forty Years Later", (1991) 7 Connecticut Journal of International Law 1, pp. 44-5 (reimpreso en METTRAUX, Perspectives, cit. nota $\mathrm{n}^{\circ}$ 2, p. 492).

${ }^{14}$ Esto nos retrotrae a Nüremberg, véase KELSEN, "Will the Judgment”, cit. nota no 2, p. 165. En cualquier caso, el "argumento de la justicia" claramente prevalece sobre la objeción a la retroactividad. En cuanto a la defensa de Nüremberg véase, RADBRUC, G., "Zur Diskussion über die Verbrechen gegen die Menschlichkeit" (1947) 2 Süddeutsche Juristenzeitung columna 131, columna 135. Véase también JESCHECK, H. H., Die Verantwortlichkeit der Staatsorgane nach Völkerstrafrecht (1952), pp. 240 y ss. quien en última instancia invoca consideraciones de justicia cuando distingue entre los crímenes contra la paz y los de lesa humanidad, sosteniendo para los primeros, la prohibición de retroactividad por su importancia en la normativa del derecho penal internacional (p. 241), mientras que permite el castigo retroactivo para los segundos, por su particular ilegalidad (p. 242). Para una posición contraria y más radical, véase GREEN, L.C., "The maxim nullum crimen sine lege and the Eichmann Trial", (1962) 38 Brit.YbIL 457, p. 471 sosteniendo que "that there is nothing in international law (...) which precludes the enactment of retroactive criminal legislation."
} 
AMBOS, KAI. "El derecho penal internacional en la encrucijada: de la imposición ad hoc a un sistema universal basado en un tratado internacional".

law ${ }^{15}$ y aún en Inglaterra, la jurisdicción madre, existe una tendencia hacia la codificación. ${ }^{16}$ Fue Lord Bingham of Cornhill, presidente del Tribunal Supremo inglés, quien realizó un fuerte y convincente llamado para la adopción de un código penal, resumiendo los argumentos a favor de la codificación en tres aspectos:

"En primer lugar, brindará claridad y accesibilidad al derecho. Segundo, dará coherencia al derecho penal. Tercero, (...) un código ofrecerá mayor certeza al derecho. Esto es particularmente importante ya que el artículo 6 del Convenio Europeo de Derechos Humanos, tal como se aplica, requiere que los delitos se definan con una precisión razonable." 17

Existen otros problemas relacionados con los tribunales ad hoc que hablan a favor de su abolición. Por razones de espacio éstos no podrán ser examinados aquí. Será suficiente mencionar solo una objeción importante, estos tribunales tienen el sabor de la justicia de los vencedores. ${ }^{18}$ Este fue el caso en Nüremberg y Tokio en el pasado y es la situación de Irak en el presente. No son verdaderos tribunales universales pero su normativa siempre fue (y es) enmarcada de acuerdo con las tradiciones legales e intereses políticos de los poderes que las crearon. En consecuencia, la justicia penal internacional ad hoc siempre fue common law, una justicia penal acusatoria sin jurado. Más importante aún resultan ser los problemas estructurales que estos tribunales sufrieron y siguen sufriendo con respecto a un juicio justo en su sentido más amplio. Si bien éstos pueden proporcionar las garantías de un juicio justo stricto sensu, es decir, el derecho a ser informado acerca de la acusación en un plazo razonable y en el idioma del acusado, el derecho a una defensa adecuada, presunción de inocencia, etc., ${ }^{19}$ tienden a ser estructuralmente tendenciosos y parciales ya que sólo investigan los crímenes cometidos por una de las partes en el conflicto. Este fue el caso en el pasado ${ }^{20}$ y sigue siéndolo en el presente, aunque no en la misma medida. ${ }^{21}$

\footnotetext{
${ }^{15}$ Para Estados Unidos véase LAFAVE, W., Principles of Criminal Law (2003), p. 62 “(...) in recent years a great many states have enacted comprehensive new criminal codes, and in the process they have usually but not always abolished common law crimes”. Para Canadá véase STUART, D., Canadian Criminal Law (2001), p. 8 (“.... widely accepted that any type of offences in Canada must derive from legislation ..."). Para Australia véase BAGARIC, M., ARENSON K.J., Criminal Laws in Australia (2007), pp. 18-19 (distinguiendo entre los diferentes territorios y estableciendo que "the Commonwealth government, in consultation with state governments, has been developing a National Criminal Code, applying to all Commonwealth offences from 15 December 2001"). Para el caso especial de Irlanda (Rep.) véase Ní CHOILÉAIN, C., Criminal Law (2006), p. 3 ("primary sources of Irish criminal law are legislation and the common law").

${ }^{16}$ Esto se sigue desde el trabajo de la Comisión de Derecho. En su reciente " $10^{\text {th }}$ Programme of Law Reform" at http://www.lawcom.gov.uk/docs/lc311.pdf, esto reafirma su compromiso con una codificación global del derecho penal (para. 2.24) pero primero debe "to undertake projects to simplify the criminal law" (para. 1.6.) y "to make codification more achievable" (para. 2.24). Véase también el trabajo "A new Homicide Act for England and Wales?", (2005) disponible en http://www.lawcom.gov.uk/docs/cp177_overview web.pdf Véase también ASHWORTH, A., Principles of Criminal Law ( ${ }^{\text {th }}$ ed. 2009), p. 8.

Citado de acuerdo al $33^{\circ}$ Informe Anual de la Comisión de Derecho, disponible en http://www.lawcom.gov.uk/docs/lc258.pdf para. 1.34 .

${ }^{\frac{1}{18}}$ Esta objeción conlleva una especie de leitmotif a través de la literatura desde la Segunda Guerra Mundial hasta la actualidad, véase por ejemplo MINEAR, R. H., Victors' justice: The Tokyo War Crimes Trial (1971); BIDDISS, M., "Victors' Justice? The Nuremberg Tribunal", (1995) 45 History Today, 40; MEEMIK, J., "Victor's Justice or the Law? Judging and Punishing at the International Tribunal for the Former Yugoslavia" (2003) 47 Journal of Conflict Resolution 140; PEARL, E. L., "Punishing Balkan War Criminals: Could the End to Yugoslavia provide an End to Victors' Justice?" (1993) 30 American Criminal Law Review 1373; DOUGHERTY, B., "Victims' Justice, Victors' Justice: Iraq's flawed Tribunal" (2004) 1 Middle East Policy 61; PESKIN, V., "Beyond Victor's Justice? The Challenge of Prosecuting the Winners at the International Tribunal for the Former Yugoslavia and Rwanda" (2005) 4 Journal of Human Rights 213; ROJO, E. C., "The Role of Fair Trial Considerations in the Complementarity Regime of the ICC: From "No Peace without Justice" to "No Peace with Victors' Justice?" (2005) 18 LJIL 829; SCHEUERMANN, L., 'Victors Justice? The Lessons of Nuremberg Applied to the Trial of Saddam Hussein" (2006) 15 Tulane Journal of International and Comparative Law 291; WINGE, B., "Why Punish War Crimes? Victors Justice and Expressive Justifications of Punishment", (2006) 25 Law and Philosophy 159; TOTANI, Y., The Tokyo War Crimes Trial: The Pursuit of Justice in the Wake of World War II (2008), pp. 246 y ss.., ZOLO D. D., La justicia de los vencedores. De Nuremberg a Bagdad (2006), pp. 178 y ss.

${ }_{19}$ Véase por ejemplo, art. 16 del Estatuto TMI (supra nota $\left.{ }^{\circ} 10\right)$ y art. 21 del Estatuto de la TPIY, UN Doc. S/Res/827 (1993).

${ }^{20}$ Claramente, en Nüremberg sólo los abogados defensores alemanes estuvieron interesados en los crímenes de las fuerzas aliadas, especialmente los Soviéticos. Esta fue la raíz de la discusión sobre la defensa "tu quoque" - véase AMBOS, Kai, Der Allgemeine Teil des Völkerstrafrechts (2nd. ed. 2004), pp. 123 y ss.

${ }^{21}$ Esta objeción no es válida para el TPIY pero sí se aplica al TPIR y a los Tribunales de Iraq y El Líbano. Mientras que los conflictos subyacentes, relevantes para estos tribunales fueron por cierto diferentes, se sigue de la competencia ratione temporis y (o et?) personae de los correspondientes tribunales de manera más o menos explícita, que todos los juicios se dirigen contra la parte que fue (militarmente) vencida en el conflicto, por ejemplo, los Hutus como autores del genocidio contras los Tutsis, Saddam Hussein y sus seguidores y las personas responsables de la muerte del ex Primer Ministro Libanés Rafiq Hariri (cfr. art. 1 Estatuto del TPIR, UN Doc. S/RES/955 [1994]; art. 1 (2) de la ley de "The Iraqi Higher Criminal Court") (sucesor del "Tribunal Especial Iraquí"
} 
Polit. crim. Vol. 5, No 9 (Julio 2010), Art. 6, pp. 237-256.

[http://www.politicacriminal.cl/Vol_05/n_09/Vol5N9A6.pdf]

\section{La Corte Penal Internacional: EI nuevo sistema universal.}

\subsection{El principio de la "tabula rasa".}

La Corte Penal Internacional (en adelante, CPI) sin duda fue establecida para convertirse en un tribunal mejor y universal. Podríamos incluso decir que la CPI, en sus fundamentos y práctica legales se diferencia de los tribunales ad hoc, especialmente del TPIY y el Tribunal Penal Internacional para Ruanda (en adelante, TPIR). En cuanto a su base jurídica, se pueden mencionar varios ejemplos en los que el Estatuto de la CPI se aparta de la normativa de los tribunales ad hoc. Así, el artículo 31 permite, en principio, la coacción en los casos en que se quite la vida a personas inocentes dejando a un lado el precedente Erdemovic. ${ }^{22}$ A su vez, los artículos 22-24 reconocen explícitamente el principio nullum crimen. Sobre este tema se volverá más adelante. En cuanto a la práctica, las decisiones de la CPI hasta aquí nos demuestran que, aún cuando se tiene en cuenta la jurisprudencia del TPIY y del TPIR, la Corte no está obligada ni guiada por ella. ${ }^{23}$ Esto puede ser demostrado mediante dos ejemplos, uno de derecho penal sustantivo y otro de procedimiento. A este enfoque lo llamo principio de tabula rasa ("borrón y cuenta nueva" o "empezar de cero"). ${ }^{24}$

2.1.1. Tabula rasa en el derecho sustantivo: coautoría y autoría indirecta.

En el caso Stakic, la Cámara de Apelaciones del TPIY sostuvo que la coautoría "no tiene respaldo en derecho internacional consuetudinario o en la jurisprudencia establecida por este tribunal". ${ }^{25}$ Esto es, como mínimo, una afirmación sorprendente, teniendo en cuenta que el modo de autoría denominado empresa criminal conjunta (JCE, según sus siglas en inglés) ${ }^{26}$ está basada en la coautoría; de hecho es en su forma pura (JCE I) un supuesto de coautoría, y en su forma extendida (JCE III), una extensión de la coautoría por actos que van más allá del acuerdo original (empresa) para imputar estos actos (excesivos) a todos los miembros de la empresa. ${ }^{27}$ En cambio, la Sala de Cuestiones Preliminares (en adelante, SCP) de la CPI en la decisión de confirmación de Lubanga, refiriéndose al artículo 25(3a) alternativa 2 del Estatuto de la CPI ("junto con otro"), ha sostenido correctamente que:

establecido por Estados Unidos el 18 de octubre de 2005) disponible en: http://law.case.edu/grotian-momentblog/documents/IST statute official english.pdf; art. 1 (1) del Estatuto del Tribunal Especial para el Líbano, Anexo al UN Doc. S/RES/1757 [2007]). Asimismo, en el caso Iraquí contra Saddam Hussein no cumplía con todos los estándares generales del juicio justo reconocidos. Para un análisis crítico véase AMBOS, Kai, PIRMURAT, S., "Das Todesurteil gegen Saddam Hussein", (2007) 62 Juristenzeitung 822; M. Sissons y A. S. Bassin, "Was the Dujail Trial Fair?" (2007) 5 JICJ 272; DE BERTODANO, S., "Were there more acceptable alternatives to the Iraqi High Tribunal?" (2007) 5 JICJ 294; SPALHOLZ, H. M., "Saddam Hussein and the IST on Trial: The Case for the ICC", (2007) 13 Buffalo Human Rights Law Review 255; para un relato explicación más positivo pero no completamente imparcial SCHARF, M. P. y NEWTON, M. A., Enemy of the State (2008).

${ }^{22}$ Para una discusión véase AMBOS, Kai, "Other grounds for Excluding Criminal Responsibility", en CASSESE, A., GAETA, P., JONES, R.W.D. (Eds.), The Rome Statute of the International Criminal Court: A Commentary, Vol. I (2002), 1003, pp. 1042 y ss.

${ }^{23}$ En el caso Prosecutor v. Thomas Lubanga Dyilo, Decision Regarding the Practices Used to Prepare and Familiarise Witnesses for Giving Testimony at Trial, Case No. ICC-01/04-01/06, 30 de noviembre 2007, para. 44. En igual sentido KREß, C., "Claus Roxins Lehre von der Organisationsherrschaft und das Völkerstrafrecht" (2006) 153 Goldthammer's Archiv für Strafrecht 304, p. 307.

${ }^{24}$ En la discusión que siguió a la conferencia mencionada más arriba (supra nota *) se sostuvo que la "tabula rasa" podía ser un término demasiado estricto dado que la CPI toma en consideración la jurisprudencia de los tribunales ad hoc. Sin embargo, sostenemos que la controversia terminológica - tabula rasa "relativa" o "absoluta" no cambia el sentido de la cuestión, es decir, el hecho de que la CPI es un nuevo tribunal con una nueva norma y, por lo tanto, una jurisprudencia nueva y autónoma. La "Tabula rasa" deja bastante claro este punto a pesar de que puede contener, como todas las frases de esta naturaleza, una cierta exageración.

${ }^{25}$ En el caso Prosecutor v. Stakic, Appeal Judgement, No. IT-97-24-A, del 22 de marzo de 2006, para 62. Para un análisis crítico de esta sentencia véase BADAR, M., "'Just Convict Everyone!'- Joint Perpetration: From Tadic to Stakic and Back Again", (2006) 6 International Criminal Law Review (ICLR) 293; crit. también AMBOS, Kai, "Joint Criminal Enterprise and Command Responsibility", (2007) 5 JICJ 159, p. 170 con nota al pie 79 (en castellano en Revista de Derecho Penal y Criminologia, Universidad Nacional de Educación a Distancia, Facultad de Derecho, 2nda Epoca, t. 19, enero 2007, pp. 39-78).

${ }^{26}$ Esta forma de responsabilidad se retrotrae a Prosecutor v. Tadic, Appeal Judgement, Case No. IT-94-1, del 15 de julio de 1999, paras. 185 y ss. Para jurisprudencia ulterior véase AMBOS, "Joint Criminal Enterprise", cit. nota n 25 , p. 160 con nota al pie $3-6$.

${ }_{27}$ Para la definición de las tres formas de JCE (forma básica, sistemática y extendida) véase Prosecutor v. Tadic, supra nota 26, paras. 196 y ss. Para un análisis crítico véase AMBOS, "Joint Criminal Enterprise", cit. nota $n^{\circ} 25$, pp. 160 y ss. 
AMBOS, KAI. "El derecho penal internacional en la encrucijada: de la imposición ad hoc a un sistema universal basado en un tratado internacional".

\begin{abstract}
"El concepto de coautoría basado en un control conjunto sobre el crimen está asentado en el principio de división de tareas esenciales con el objetivo de cometer una conducta ilícita entre dos o más personas actuando de manera concertada. Por lo tanto, a pesar de que ninguno de los participantes resulta el ofensor principal, ya que todos dependen unos de otros para la comisión, todos comparten la responsabilidad porque cada uno de ellos puede frustrar la comisión del crimen si no lleva adelante su parte de la tarea."28
\end{abstract}

Con esta afirmación la SCP opta por un modelo diferenciado de participación que está contenido en el artículo 25(3). ${ }^{29}$ De este modo, no sólo reconoce la coautoría como una de las posibles formas de participación en ese sistema sino también, y fundamentalmente, determina la autoría como una forma de examinar el control o dominio del acto basado en un clásico ejemplo alemán (doctrina española, portuguesa y de Latinoamérica), es decir, en el "dominio funcional del hecho" (funktionelle Tatherrschaft). ${ }^{30}$ Así, la Sala claramente se aparta de la jurisprudencia del TPIY, que sólo en una sentencia siguió un abordaje semejante (en la sentencia de la Sala de Primera Instancia en el caso Stakic, ${ }^{31}$ rotundamente rechazado por la Sala de Apelaciones citada anteriormente). La Sala también se aparta de la doctrina de la JCE, por lo menos, en lo que va más allá de la mera coautoría en el sentido del artículo 25(3a) del Estatuto de la CPI, es decir, (al menos) en su forma extendida (JCE III). ${ }^{32}$ Nos queda por ver si esta primera decisión anuncia el final de la innovación más notoria de los tribunales ad hoc. ${ }^{33}$

La Sala también analiza la comisión de crímenes por conducto de otra persona de conformidad con el artículo 25(3a) alternativa 3 del Estatuto de la CPI ("por conducto de otra persona"), ${ }^{34}$ y considera que esta construcción también es posible con un autor completamente responsable o culpable directo, por ejemplo, en el caso del autor (indirecto) detrás del autor (directo) (Täter hinter dem Täter). ${ }^{35}$ Este punto de vista está justificado por el último párrafo del artículo $25(3 \mathrm{a})$ del Estatuto de la CPI ("sea éste o no penalmente responsable") ${ }^{36}$ y por jurisprudencia nacional. Así, independientemente de la completa responsabilidad penal del autor directo, el hombre de atrás (Hintermann $)^{37}$ fue encontrado responsable en los casos en los que tuvo dominio sobre el autor directo a través de una estructura jerárquica organizacional, por ejemplo, cuando él o ella

${ }^{28}$ Prosecutor v. Thomas Lubanga Dyilo, Decision on the Confirmation of Charges, Case No. ICC-01/04-01/06(803), de 29 de enero de 2007, para. 342, citando Prosecutor v. Stakic, Trial Judgement, Case No. IT-97-24, del 31 de julio de 2003, para. 440 (Traducción inglesa realizada por la Corte).

${ }^{29}$ Para un análisis detallado AMBOS, Kai, “Art. 25 Individual Criminal Responsibility”, en TRIFFTERER, O., (ed.), Commentary on the Rome Statute of the International Criminal Court (2008), impresión especial, nm. 7 y SS.

${ }^{30}$ Véase también SATZGER, H., Internationales und Europäisches Strafrecht (2010), $§ 15$ nm. 59; WEIGEND, T., "Intent, Mistake of Law, and Co-Perpetration in the Lubanga Decision on Confirmation of Charges", (2008) 6 JICJ 471, pp. 478 y ss.; MODOLELL, J. L., "Problemas de Autoría en la Sentencia del 29 de Enero de 2007 de la Sala de Cuestiones Preliminares I de la Corte Penal Internacional (Confirmación de Cargos Contra Thomas Lubanga Dyilo)", en AMBOS, Kai, DE HOYOS, M. (eds.), Cuestiones Esenciales en la Jurisprudencia de la Corte Penal Internacional (2008), p. 91, pp. 93 y ss.; AMBOS, “Art. 25 Individual”, cit. nota n 29, nm. 9a. Sobre esta doctrina véase el trabajo fundamental de ROXIN, Claus, Täterschaft und Tatherrschaft (2006), pp. 275 y ss., y 719 y ss. Esta jurisprudencia fue seguida en la segunda confirmación de cargos de la CPI en el caso Prosecutor v. Katanga, Decision on the confirmation of charges, Case No. ICC-01/04-01/07-, del 30 de septiembre de 2008, así como en la tercera confirmación de cargos de la Corte en el caso Prosecutor v. Jean-Pierre Bemba Gombo, ICC 01/05-01/08, del 15 de junio de 2009, donde los argumentos vertidos en los casos anteriores fueron ampliados y profundizados. Para un análisis detallado de este último caso véase AMBOS, Kai, "Critical issues in the Bemba confirmation decision”, (2009) 22 LJIL 715; en castellano en Revista Penal (España) 25 (enero 2010), 12-21.

${ }^{31}$ Prosecutor v. Stakic, supra nota ${ }^{\circ} 28$, para. 439 y ss.

${ }^{32} \mathrm{Si}$ la forma sistemática de la JCE, denominada JCE II, constituye una mera coautoría o una forma extendida de responsabilidad, está en discusión, véase al respecto AMBOS, K., Amicus Curiae for the Extraordinary Chambers in the Courts of Cambodia concerning Crimina,l Case File No. 001/18-07-2007-ECCC/OCIJ (PTC 02), 27 de octubre de 2008, pp. 13 y ss., disponible en www.eccc.gov.kh/english/court doc.list.aspx

${ }^{33}$ Véase también WEIGEND, "Intent, Mistake of Law", cit. nota n ${ }^{\circ} 30$, p. 478.

${ }^{34}$ Para un análisis más detallado véase AMBOS, “Art. 25 Individual” cit. nota ${ }^{\circ}$ 29, nm. 20 (completa) con más referencias.

${ }^{35}$ Prosecutor v. Lubanga, supra nota $n^{\circ} 28$, para. 339. Véase también la decisión más reciente en Prosecutor $v$. Germain Katanga and Mathieu Ngudjolo Chui, Decision on the confirmation of charges, Case No. ICC-01/0401/07, 30 de septiembre de 2008, para. 480 y ss. ("control sobre el alcance del crimen").

36 ESER, A., "Individual Criminal Responsibility", en CASSESE/GAETA/JONES, The Rome Statute, cit. nota ${ }^{\circ}$ 22, p. 767, p. 794; AMBOS, “Art. 25 Individual”, cit. nota ${ }^{\circ} 29$, nm. 13.

${ }^{37}$ Con relación a estas expresiones (alemanas) es útil referirse a la reciente traducción del Código Penal alemán de M. Bohlander's (The German Criminal Code - A Modern English Translation, (2008), p. 84) donde se empleó el término "hinterman" refiriéndose a otras palabras prestadas del alemán a la terminología del inglés, como "hinterland", que sugiere que los angloparlantes se familiarizarán con la connotación del prefijo "hinter"- y podrán adaptarlo a nuevas combinaciones. 
tuviera Organisationsherrschaft. ${ }^{38}$ Esta doctrina fue reconocida y aplicada por los tribunales nacionales (Eichmann, ${ }^{39}$ los Generales Argentinos, ${ }^{40}$ Matanzas en las Fronteras de Alemania Oriental $^{41}$ ). Así, la Sala se diferencia nuevamente de la jurisprudencia del TPIY y del TPIR, que hasta ahora no ha reconocido un autor indirecto por conducto de otra persona. En la decisión de confirmación de cargos en el caso Katanga/Ngudjolo Chui la Sala de Cuestiones Preliminares I sostuvo explícitamente que "este es un buen ejemplo de la necesidad de no transferir mecánicamente la jurisprudencia de los tribunales ad hoc al sistema de la Corte". ${ }^{42}$

\subsubsection{Tabula Rasa en el procedimiento: preparación (proofing) de testigos}

Mientras que no existen desacuerdos entre la Oficina del Fiscal (OTP según sus siglas en inglés) y las Salas de la CPI en cuanto a permitir la familiarización de los testigos, por ejemplo, con la infraestructura y procedimientos de la Corte en general, ${ }^{43}$ sí existen tales desacuerdos respecto de la preparación (proofing), es decir, "la práctica por la cual se mantiene una reunión entre una parte en el proceso y un testigo, antes de que el testigo declare en la Corte, con el propósito de reexaminar la prueba del testigo para proporcionar un testimonio más preciso, completo y eficiente."44 Para la OTP esta es una práctica necesaria y útil y se basa, inter alia, en la jurisprudencia establecida por los tribunales ad hoc que comparten plenamente esta visión. ${ }^{45}$ Sin embargo, las salas de la CPI, aun cuando la toman en cuenta, no se sienten obligadas por esta jurisprudencia $^{46}$ y se apartan conscientemente de ella, considerando que la preparación de testigos (witness proofing) no es jurídicamente admisible ${ }^{47}$ ni necesaria. ${ }^{48} \mathrm{El}$ argumento de las

38 Véase ROXIN, Täterschaft und Tatherrschaft, cit nota $\mathrm{n}^{\circ} 30, \mathrm{pp} .242$ y ss., pp. 704 y ss.; para una discusión
adicional véase AMBOS, "Art. 25 Individual”, cit. nota $\mathrm{n}^{\circ} 29, \mathrm{~nm} .10-11$.
${ }^{39}$ Attorney General v. Eichmann, Judgment of the Jerusalem District Court, Case No. 40/61, 12 de diciembre de
$1961,(1968) 36$ International Law Reports, pp. 236-7, para. 197.
${ }^{40}$ Cámara Nacional de Apelaciones en lo Criminal y Correccional de la Capital, 9 de diciembre de 1985, 309-I/II,
Colección Oficial de Fallos de la Corte Suprema de Justicia de la Nación, Fallos: 33: 1657, pp. 1601-2.
${ }^{41}$ BGHSt (Official Collection of the Supreme Court Judgements in Criminal Matters) 40, 218, pp. 236 y ss.; para
ver la jurisprudencia posterior BGHSt 45, 270, 296; BGHSt 48, 77, 91 .
${ }^{42}$ Prosecutor v. Katanga, supra nota $\mathrm{n}^{\circ}$ 35, para. 508. En este mismo sentido WERLE, G., "Individual Criminal Responsibility in Article 25 ICC Statute", (2007) 5 JICJ 953, pp. 961-2. Del mismo modo en el caso Prosecutor v. Bemba, supra nota $\mathrm{n}^{\circ} 30$, para. 78, la SCP implícitamente aplicó la doctrina de la autoría indirecta a través de una estructura jerárquica institucional, ya que atribuyó a Bemba el control sobre los crímenes cometidos por sus tropas "como consecuencia de su autoridad sobre su organización militar". Véase también aplicando implícitamente la teoría de la autoría indirecta a través de una institución jerárquica institucional Prosecutor v. Al Bashir, Arrest warrant decision, ICC-02/05-01/09, 4 de marzo de 2009, para. 213. Sobre este último caso véase también VAN DER WILT, H., "The Continuous Quest for Proper Modes of Criminal Responsibility", (2009) 7 JICJ 307, $313-314$.

${ }^{43}$ Después de una confusión inicial, la Oficina del Fiscal de la CPI adoptó la posición de la SCP I (Prosecutor $v$. Thomas Lubanga Dyilo, Decision on the Practices of Witness Familiarisation and Witness Proofing, Case No. ICC-01/04-01/06, 8 de noviembre de 2006, para. 18 y ss., 28 y ss.) y de la Sala de Primera Instancia I (SPI I) (Prosecutor v. Thomas Lubanga Dyilo, Decision Regarding the Practices Used to Prepare and Familiarise Witnesses for Giving Testimony at Trial, Case No. ICC-01/04-01/06, 30 de noviembre de 2007, para. 28, 53, 57) en cuanto a que la familiarización debe ser distinguida de la preparación (proofing) y se encuentra dentro de la competencia de la Unidad de Víctimas y Testigos de la Corte (UVT) (Prosecutor v. Thomas Lubanga Dyilo, Prosecution Submissions Regarding the Subjects that Require Early Determination: Procedures to be Adopted for Instructing Expert Witnesses, Witness Familiarization and Witness Proofing, Case No. ICC-01/04-01/06-952, 12 de septiembre de 2007, para. 14).

${ }_{45}$ Presentaciones de la Fiscalía, supra nota $\mathrm{n}^{\circ} 43$, para. 15.

${ }^{45}$ Prosecutor v. Limaj et al., Decision on the Defence Motion on Prosecution Practice of Proofing Witnesses, Case No. IT-03-66-T, 10 de diciembre de 2004, p. 2 ("aceptado desde el comienzo de este tribunal"); en el mismo sentido, Prosecutor v. Milutinovic et al., Decision on Ojdanic Motion to Prohibit Witness Proofing, Case No. IT05-87-T, 12 de diciembre de 2006, para. 15 ("una base diaria de los últimos trece años"); Prosecutor v. Karemera et al., Decision on Interlocutory Appeal Regarding Witness Proofing, Case No. ICTR-98-44-AR73.8, 11 de mayo de 2007, para. 9 y ss.; Prosecutor v. Sesay et al., Case Decision on the Gbao and Sesay Joint Application for the Exclusion of the Testimony of Witness, No. SCSL-04-I5-T, TF1-141, 26 de octubre de 2005, para. 33 refiriéndose a Prosecutor $v$. Limaj et al., y sosteniendo que la prueba es una "legitimate practice that serves the interests of justice". A favor de éste enfoque KAREMAKER, R. TAYLOR III, D., PITTMAN, T. W., "Witness Proofing in International Criminal Tribunals: A Critical Analysis of Widening Procedural Divergence", (2008) 21 LJIL 683; mi crítica "«Witness Proofing» before the ICC. A reply to Karemaker, Taylor and Pittman", (2008) 21 LJIL 911; en contra KAREMAKER, R. TAYLOR III, D., PITTMAN, T. W., "Witness proofing in International Criminal Tribunals: Response to Ambos", (2008) 21 LJIL 917.

${ }^{46}$ ICC-TC I, supra nota $\mathrm{n}^{\circ} 43$, paras. 44-5. Los tribunales ad hoc adoptaron el mismo criterio: Prosecutor $v$. Karemera et al., supra nota ${ }^{\circ} 45$, para.7; Prosecutor v. Milutinovic et al., supra nota ${ }^{\circ} 45$, para. 13.

${ }^{47}$ ICC-PTC I, supra nota ${ }^{\circ} 43$, para. 42 ("not embraced by any general principle of law"). 
AMBOS, KAI. "El derecho penal internacional en la encrucijada: de la imposición ad hoc a un sistema universal basado en un tratado internacional".

salas descansa en la interpretación razonada del Estatuto y de sus instrumentos adicionales, así como en la estructura inquisitorial-adversarial mixta del procedimiento ante la CPI. ${ }^{49}$ Las salas se refieren, por ejemplo, al concepto de testigo como testigo de la Corte (de la verdad) para argumentar que esta interpretación prohíbe cualquier forma de preparación de un testigo por una de las partes. ${ }^{50}$

En otro trabajo expresé que esta idea de las salas es correcta tanto desde la perspectiva de la normativa de la CPI como de la del derecho comparado. ${ }^{51}$ En cualquier caso, la controversia muestra una vez más que la CPI se aparta con plena conciencia del enfoque de los tribunales ad hoc.

\subsection{Ningún sistema preconcebido.}

George Fletcher, refiriéndose a la Parte General (Principios Generales) del Estatuto de la CPI, sostiene que el Estatuto resuelve la cuestión del sistema a favor del sistema bipartito (distinguiendo entre actus reus/mens rea por un lado y por el otro, delitos/defensas) asegurando de tal manera la supervivencia de este sistema "en muchas partes del mundo". 52 Tal como sostuve en otro trabajo, esto no es correcto. ${ }^{53}$ En primer lugar surge claramente de los travaux ${ }^{54} \mathrm{y}$ del mismo Estatuto que los redactores quisieron nada menos que optar por una teoría específica del crimen o de la imputación. Las negociaciones fueron prácticas y estuvieron guiadas por el deseo de encontrar ciertas reglas operativas y consensuadas respecto de la parte general. Más aún, el Estatuto no toma partido y en cambio trata de utilizar terminología "neutral" por ejemplo "circunstancias excluyentes de responsabilidad" en lugar de defensas, para evitar cualquier preferencia por uno u otro sistema. Incluso, si la redacción del Estatuto indicase una preferencia por un sistema particular, la exclusiva dependencia de este texto sería cuestionable. Por cierto el mismo Fletcher utilizó un enfoque distinto en su obra fundacional Rethinking Criminal Law cuando trató de adoptar la doctrina alemana al derecho penal norteamericano intentando superar redacciones contradictorias de los códigos y de los precedentes judiciales. ${ }^{55}$

Del mismo modo, el Estatuto tampoco decide la cuestión en torno al sistema procesal. ${ }^{56}$ Existe consenso general respecto de que el procedimiento ante la CPI es mixto en cuanto contiene elementos estructurales tanto del sistema adversarial como del inquisitivo. ${ }^{57} \mathrm{Sin}$ dudas, como se explicó anteriormente, ${ }^{58} \operatorname{los}$ términos "adversarial"/ "inquisitivo" tienen que ser utilizados con

${ }^{48}$ ICC-TC I, supra nota $\mathrm{n}^{\circ}$ 43, para. 46-52 (señalando el serio riesgo de que se distorsione la verdad a causa del ensayo previo del testimonio a prestar en corte, y la consecuente falta de "espontaneidad provechosa" durante el testimonio en el juicio).

${ }^{49}$ Véase infra notas $\mathrm{n}^{\circ} 57$ y ss. y texto anexo.

${ }^{50}$ ICC-PTC I, supra nota $\mathrm{n}^{\circ} 43$, para. 26; conc. ICC-TC I, supra nota $\mathrm{n}^{\circ} 43$, para. 33-4.

51 AMBOS, Kai, "Witness Proofing before the ICC: Neither Legally Admissible Nor Necessary", en STAHN, C., SLUITER, G. (eds.), The Emerging Practice of the International Criminal Court (2009), p. 599 (en castellano en: AMBOS K., DE HOYOS, M., Hoyos, Cuestiones esenciales en la jurisprudencia de la Corte Penal Internacional, Granada: Comares, 2008, pp. 1-22); AMBOS, “«Witness Proofing» before the ICC”, cit. nota n 45 p. 911.

${ }^{52}$ FLETCHER, G. P., The Grammar of Criminal Law: American, Comparative, and International. Volume One: Foundations (2007), p. 46.

${ }^{53}$ AMBOS, Kai, “Toward a Universal System of Crime: Comments on George Fletcher's Grammar of Criminal Law”, (2007) 28 Cardozo Law Review 2647, pp. 2669-771.

${ }^{54} \mathrm{Si}$ bien no hay Travaux oficiales del proceso de Roma, las negociaciones fueron documentados por M. C. Bassiouni, en The Legislative History of the International Criminal Court, Vol. I-III, (2005). La mayoría de los documentos también están disponibles en: www.icc-cpi.int/legaltools, trabajos preparatorios de la ICC.

${ }^{55}$ FLETCHER, G. P., Rethinking Criminal Law (1978), pp. 575 y ss.

${ }^{56}$ Para un análisis detallado en comparación con el trabajo jurídico del TPIY véase AMBOS, Kai, "The Structure of International Criminal Procedure: 'Adversarial', 'Inquisitorial' or 'Mixed'?”, en BOHLANDER, M. (ed.), International Criminal Justice: A Critical Analysis of Institutions and Procedures (2007), pp. 429-503.

${ }^{57}$ Cfr. FERNÁNDEZ DE GURMENDI, S., "The Elaboration of the Rules of Procedure and Evidence", en LEE, R. S. (ed.), ICC: Elements of Crimes and Rules of Procedure and Evidence (2001), 235, p. 251; FRIMAN, H., "The Rules of Procedure and Evidence in the Investigative Stage", en FISCHER, H., KREß, C., y LÜDER, S. R. (eds.), International and National Prosecution of Crimes under International Law (2001), 191, pp. 214, 217; HARHOFF, F., en ibid., 645, p. 650; ORIE, A., "Accusatorial v. Inquisitorial Approach in International Criminal Proceedings etc.", en CASSESE/GAETA/JONES, The Rome Statute, cit. nota n 22, pp. 1475 y ss., 1493-4; ESER, A., "Auf dem Weg zu einem internationalen Strafgerichtshof etc.", en COURAKIS, N., (ed.), Die Strafrechtswissenschaft im 21. Jahrhundert: Festschrift für Dionysios Spinellis (2001), 339, p. 365; HOFSTETTER, E., Das Verfahrensrecht Internationales Strafgerichte Zwischen Common Law und Civil Law $(2005)$, p. 24.

${ }^{58}$ AMBOS, Kai, “International Criminal Procedure: ‘Adversarial', 'Inquisitorial’ or 'Mixed'?”, (2003) 3 ICLR 1, pp. 2 y ss. (en castellano publicado en Revista General de Derecho Procesal IUSTEL, núm. 3, 2004, http://www.iustel.com/revistas; Derecho Penal Contemporáneo, Legis, Colombia, No. 7, Abril-Junio 2004, 5-56; Revista Brasileira de Ciências Criminais, Instituto Brasileiro de Ciências Criminais, Sao Paulo, 57, novembredezembro 2005, 159-211). 
cautela y sólo en sentido general de la aún existente división entre el common law y el derecho continental o civil, ${ }^{59}$ mejor expresada por la dicotomía entre un sistema coordinado y horizontal de dos partes versus un enfoque del caso liderado por el juez (instruktorisch), de forma jerárquica y vertical. ${ }^{60}$ Debemos recordar que la preeminencia inicial del common law en las discusiones del Comité Preparatorio en $1995^{61}$ recién fue balanceada por el llamado "Borrador Francés" presentado en 1996. ${ }^{62}$ Este Borrador fue crucial para generar verdaderas discusiones entre el sistema del common law y el continental, que finalmente concluyeron, al menos en un sentido normativo, en la convergencia de ambos sistemas en el Estatuto de la CPI y las Reglas de Procedimiento y Prueba (RPP). ${ }^{63}$ En consecuencia, términos como cross-examination y otra terminología típica (latiguillos) de los abogados pertenecientes a ambos sistemas jurídicos, están notoriamente ausentes del Estatuto y de las RPP. Los redactores quisieron dejar en claro que lo que se buscaba era un procedimiento verdaderamente mixto. ${ }^{64}$ Como resultado, la aplicación práctica del marco procesal de la CPI dependerá, en última instancia, de la formación legal de los jueces a quienes se los ha dotado de suficiente discrecionalidad para dirigir los juicios de acuerdo a sus propias experiencias y preferencias. ${ }^{65}$ Resulta claro que un sistema verdaderamente mixto, sui generis, requiere de fiscales, abogados defensores y jueces que tengan conocimiento de ambos sistemas jurídicos (common law y continental) y que sean capaces de ver más allá de sus propios sistemas legales. ${ }^{66}$ La práctica de los tribunales ad hoc, especialmente la del TPIY, demuestra que los límites nacionales del proceso penal, pueden ser resueltos con una creciente experiencia y práctica en un sistema de justicia penal internacional, que se dirige hacia una convergencia armónica del sistema inquisitivo y del sistema adversarial.

\section{3. ¿Un derecho creado por el juez?}

La amplitud y flexibilidad del Estatuto de la CPI permite a los jueces tener una amplia discrecionalidad. En el procedimiento dependerá de su formación jurídica que el juicio sea más adversarial o, por el contrario, más inquisitivo. En el derecho sustantivo, el recurso a los principios generales en el sentido del artículo 21 será vital para completar las lagunas del Estatuto de la CPI. El significado de los principios generales y por lo tanto del derecho penal comparado de conformidad con el régimen de la CPI ha sido demostrado por Fabián Raimondo. ${ }^{67}$ Coincido con la esencia de sus conclusiones, ${ }^{68}$ que pueden ser resumidas de la siguiente manera:

- Las certezas de los principios generales del derecho penal contribuyen al desarrollo del derecho penal internacional echando luz sobre cuestiones no reguladas por el derecho convencional y consuetudinario.

- Los principios generales tienen, en la mayoría de los casos, la función de completar los vacíos legales del derecho penal internacional.

\footnotetext{
${ }^{59}$ En el mismo sentido ORIE, “Accusatorial v. Inquisitorial”, cit. nota ${ }^{\circ} 57$, pp. 1440 y ss. con varias referencias. ${ }^{60}$ Véase la principal obra de DAMASKA, Mirjan R., Two Faces of Justice and State Authority (1986), pp. 16 y ss. Para una buena explicación véase también TRÜG, G., "Erkenntnisse aus der Untersuchung des USamerikanischen plea bargaining-Systems for den Deutschen Absprachendiskurs", (2008) 120 Zeitschrift für die Gesamte Strafrechtswissenschaft 331, pp. 347, 364 y ss., 367 y ss.

${ }^{61}$ Cfr. BITTI, G., "Two Bones of Contention between Civil and Common Law: The Record of the Proceedings and the Treatment of Concursus Delictorum", en FISCHER/KREß/LÜDER, International and National Prosecution, cit. nota $\mathrm{n}^{\circ} 57,273$, p. 274 en donde expresa que el dominio del common law era tal que decide "advertir" a su gobierno que "era necesaria una reacción fuerte a fin de evitar un sistema jurídico de common law puro. Sobre la evolución de su redacción véase FERNÁNDEZ DE GURMENDI, "The Elaboration of the Rules", cit. nota $\mathrm{n}^{\circ} 57$, pp. 217 y ss.

${ }^{62}$ UN Doc A/AC.249/L.3 (1996).

${ }^{63}$ Incluso S. Fernández de Gurmendi, presidente argentina del grupo de trabajo de Cuestiones Procesales, que es bastante crítica del borrador francés mencionado en el texto, admite que fue recién en 1997, es decir, más de un año después de que éste fuera presentado, que los delegados "aceptaron que el futuro de los procedimientos de la Corte no iban a reflejar ni podían reflejar visiones nacionales particulares sino que deberían ser híbridos" (supra nota 57 , p. 220). Véase también KREß, C. en GRÜTZNER, PÖTZ, P.G., y KREß, C., Internationaler Rechtshilfeverkehr in Strafsachen (2002), looseleaf, instalment 56, Vol. 4, III 26, nm. 95.

${ }^{64}$ Cfr. KREß, C., "Witnesses in Proceedings before the ICC etc.", en FISCHER/KREß/LÜDER, International and National Prosecution, cit. nota $n^{\circ} 57,309$, p. 352; ORIE, "Accusatorial v. Inquisitorial", cit. nota $n^{\circ} 57, \mathrm{p}$. 1480 con nota al pie 161,1488 con nota al pie 175 .

${ }_{65}$ Véase también KREß, "Witnesses in Proceedings", cit. nota $n^{\circ} 64$, pp. 353, 382 ("open procedural framework"); igualmente ORIE, “Accusatorial v. Inquisitorial”, cit. nota n 57, pp. 1493, 1494.

${ }^{66}$ Véase también HARHOFF, supra nota ${ }^{\circ} 57$, p. 654.

${ }^{67}$ RAIMONDO, F., General Principles of Law in the Decisions of International Criminal Courts and Tribunals (2007).

${ }^{68}$ Ibid, pp. 201-2.
} 
AMBOS, KAI. "El derecho penal internacional en la encrucijada: de la imposición ad hoc a un sistema universal basado en un tratado internacional".

- El método de derecho comparado tal como es empleado por los tribunales y cortes de derecho penal internacional requiere mejoras. En especial con respecto a la selección de los sistemas legales nacionales analizados. Para mejorar la legitimidad de un principio general de derecho, la muestra debe incluir, pero no limitarse, a los sistemas jurídicos más importantes del mundo, por ejemplo, el anglo-americano "common law" o el sistema romano-germánico "derecho continental”. ${ }^{69}$ Además, de los sistemas más trascendentes del common law y del derecho continental, otros sistemas menos importantes o de otras culturas, como por ejemplo el Islam, ${ }^{70}$ deberían incluirse.

- Las diferencias estructurales entre los sistemas jurídicos nacionales y el derecho (penal) internacional no han sido un serio obstáculo en la transferencia de los principios legales de los primeros a los últimos. En última instancia, el contenido de los principios puede ser adaptado, si fuera necesario, a las especificidades del derecho internacional.

Por lo tanto, resulta claro que los principios generales tendrán que brindarnos el material normativo para encontrar soluciones apropiadas en los casos concretos. Claramente, los principios en sí mismos son demasiado abstractos para la solución de los casos reales. Su aplicación concreta y apropiada queda en manos de los jueces, quienes así adquieren mayor discrecionalidad. Todo esto parece resumirse en el famoso dictum de Oliver Wendell Holmes:

“Los principios generales no deciden casos concretos... la decisión dependerá del juicio o intuición, que son más sutiles que cualquiera de las premisas más importantes que hayan sido expresadas". 71

Es indiscutible que la discrecionalidad judicial y los principios generales no convierten al sistema de Roma en un sistema de derecho producido por el juez comparable al clásico common law, en el que el juez puede incluso crear delitos y eliminar defensas. ${ }^{72}$ Sin embargo, aún surge la cuestión de si en este sistema puede existir un principio de legalidad estricto.

\section{4. ¿Legalidad estricta?}

Los artículos 22-24 del Estatuto de la CPI establecen el principio nullum crimen en todas sus formas (leges scripta, stricta, certa y praevia). ¿Esto significa que los jueces de la CPI no deben recurrir al derecho aplicable de acuerdo al significado del artículo 21 para ampliar su derecho penal aplicable y/o completar los vacíos legales en el Estatuto? En mi opinión, la cuestión requiere un enfoque con dos elementos, distinguiendo entre la parte general y los delitos. En cuanto al primero, parece sensato realizar una distinción más entre las reglas de la imputación y las circunstancias eximentes de responsabilidad. En cuanto al último, está claro que el principio nullum crimen no impide la posibilidad de recurrir a circunstancias adicionales excluyentes de responsabilidad. Este recurso y también la interpretación extensiva de las condiciones reconocidas en el Estatuto favorecerían al acusado y está establecido, en forma explícita, en el artículo 31(3):

\footnotetext{
${ }^{69}$ Este es el momento de decir algo acerca de la terminología. El difundido uso de los términos common law y derecho continental (civil law) para referirse al sistema anglo americano y romano germánico respectivamente resulta problemático al menos por dos razones. Primero, el término "common law" se refiere stricto sensu solamente al derecho inglés consuetudinario e ignora el "derecho escrito" ("statute law") tal como se da hoy en día en las antiguas colonias inglesas (supra nota $\mathrm{n}^{\circ} 15$ ). En segundo lugar, el término "civil law" genera malos entendidos, al menos en idiomas distintos del inglés, ya que "civil law" puede hacer referencia al derecho de los contratos, de daños, etc. Acerca de esta terminología también puede consultarse FAIRCHILD, E. S., DAMMER H.S., Comparative Criminal Justice Systems, (2001), pp. 47 y ss.. Asimismo, la clasificación en familias jurídicas se ha vuelto cada vez más controvertida. (cfr. GORDLEY, J., "Common Law and Civil Law: Eine Uberholte Unterscheidung", (1993) 1 Zeitschrift für Europäisches Privatrecht, 498, 499 y ss; HEISS, H., "Hierarchische Rechtskreiseinteilung”, (2001) 100 Zeitschrift für Vergleichende Rechtswissenschaft 396, pp. 399 y ss.; HUSA, D., "Classification of Legal Families Today. Is it Time for a Memorial Hymn?", (2004) 56 Revue Internationale de Droit Comparé 11).

${ }^{70}$ Véase infra nota $\mathrm{n}^{\circ} 108$.

71 Lochner v. New York, 198 US 45, p. 76 (1905), Voto disidente del Juez Holmes, disponible en: http://supct.law.cornell.edu/supct/html/historics/USSC_CR_0198_0045_ZS.html

${ }^{72}$ Véase el artículo original de SMITH, A. T. H., "Judicial Law Making in the Criminal Law", (1984) 100 Law Quarterly Review 46. En la concepción jurídica del delito "conspiracy to corrupt public morals" véase Shaw $v$. Director of Public Prosecutions (DPP), House of Lords, Judgment of 4 May 1961, Appeal Cases (AC) 1962, 220 and Knuller v. DPP, House of Lords, Judgment of 14 June 1971, AC 1973, 435; sobre la eliminación retroactiva del eximente de violación dentro del matrimonio $R v$. R. House of Lords, Judgment of 23 October 1991, AC 1992, 599 y GILES, M., "Judicial Law-Making in the Criminal Courts: The Case of Marital Rape", (1992) Crim. L. Rev. 407.
} 
“... la Corte podrá tener en cuenta una circunstancia eximente de responsabilidad penal distinta de las indicadas en el párrafo 1 siempre que dicha circunstancia se desprenda del derecho aplicable de conformidad con el artículo 21."

En el mismo sentido, el principio nullum crimen se aplica a las formas de responsabilidad, en especial al artículo 25 , porque esas reglas conectan la conducta individual a los crímenes y como tales deben ser consideradas como la base para la responsabilidad penal. En este sentido, existen por lo menos dos posibles conflictos con el principio nullum crimen. En primer lugar, con respecto a la responsabilidad general por omisión, surge la pregunta acerca de si esa responsabilidad puede existir a pesar de la ausencia de una disposición específica en este sentido en el Estatuto de la CPI. ${ }^{73}$ La jurisprudencia de los tribunales ad hoc generalmente han aceptado que la responsabilidad de conformidad con el artículo 7(1) del TPIY incluye además la comisión por omisión. ${ }^{74} \mathrm{La}$ SCP en el caso Lubanga, parece sostener el mismo punto de vista, refiriéndose a "acciones u omisiones" con respecto al concepto de crimen como está contenido en el artículo $30 .^{75}$ La doctrina también considera que la conducta abarca acciones positivas u omisiones, y que una responsabilidad general por omisiones pueden derivarse del derecho consuetudinario y/o de los principios generales. ${ }^{76}$ Más aún, una omisión puede implicar apoyo moral, y por lo tanto ser calificada como complicidad. ${ }^{77}$ En resumen, la responsabilidad por omisión es claramente parte del derecho penal internacional general y también está contenida en otras disposiciones del Estatuto (en especial art. 28, pero también en algunos delitos, como por ejemplo, art. 8(2b)(xxv) ("inanición") o art.7(1b) concomitantemente con el (2b) ("privación")). Sin embargo, en el caso de las disposiciones que no se refieren clara y explícitamente a una omisión como base de la conducta criminal, una estricta comprensión de nullum crimen sugiere que la responsabilidad por una omisión está excluida. ${ }^{78}$

En segundo lugar, con respecto a la -ya mencionada ${ }^{79}$ - responsabilidad por JCE III, la cuestión que surge es cómo esta extensión de la responsabilidad, que va más allá de la mera coautoría, puede ser cubierta por el artículo 25(3) del Estatuto de la CPI y por lo tanto, cómo su eventual aplicación ante la CPI puede ser reconciliada con la interpretación estricta y la prohibición de analogía, íntimamente ligada a la primera, requisitos del principio del nullum crimen (véase art. 22(2) 1 párrafo). Una interpretación literal del artículo 25(3) parece indicar que la JCE III no puede ser subsumida bajo el sub-parágrafo (c) ni bajo el sub-parágrafo (d). ${ }^{80}$ En cuanto al subparágrafo (c), éste difiere en el elemento subjetivo de la JCE II y III: ya que requiere, por un lado, conocimiento o intención conforme el significado del artículo 30 del Estatuto de la CPI y, por el otro, un acto "con el propósito de facilitar la comisión de tal crimen". En cuanto al subparágrafo (d) la situación es más compleja. Mientras la Sala de Apelaciones en el caso Tadic consideró que el sub-parágrafo (d) contiene una noción sustancialmente similar y mantiene la doctrina de la $\mathrm{JCE}^{81}$ este punto de vista adolece de una falta de diferenciación entre las

\footnotetext{
${ }^{73}$ Me refiero a una disposición explícita que contiene los requisitos o condiciones de la responsabilidad por omisión, véase por ejemplo, sec. 13 de la Strafgesetzbuch alemán requiriendo en particular una posición específica de la protección hacia el interés jurídico amenazado (posición de un garante - Garantenstellung).

${ }^{74}$ Prosecutor v. Tadic, supra nota ${ }^{\circ}$ 26, para. 188; conc. Prosecutor v. Kordic and Cerkez, Judgment, Case No. IT-95-14/2-T, 26 de febrero de 2001, paras. 375-6; Prosecutor v. Musema, Judgment, Case No. ICTR-96-13-A, 27 de enero de 2000, para. 123. La Sala de Apelaciones de Celibici, sin embargo, sostuvo que la negativa a otorgar la libertad a un prisionero no es una omisión punible en los términos del art. 7(1) Estatuto TPIY (Prosecutor v. Delalic et al., Appeal Judgment, Case No. IT-96-21-A, 20 de febrero de 2001, paras. 342-3, 376). ${ }^{75}$ Prosecutor v. Lubanga, supra nota $\mathrm{n}^{\circ} 28$, para. 351.

${ }^{76}$ Véase para un análisis profundo DUTTWILLER, M., "Liability for Omission in ICL", (2006) 6 ICLR 1, que concluye que, si bien no puede afirmarse la existencia de una norma consuetudinaria que establezca la responsabilidad por omisión, ésta existe como principio general (54 y ss., 60); para el mismo resultado, aunque basándose en la costumbre y/o los principios generales, véase WERLE, G., Völkerstrafrecht (2007), mn 596 y ss., (602); CRYER, R., et al., An Introduction to International Criminal Law and Procedure (2007), 302; CASSESE, A., International Criminal Law (2008), p. 233; BORSARI, R., Diritto Punitivo Sovranazionale come Sistema (2007), pp. 318,325 .

7 Para el concepto amplio de complicidad en la jurisprudencia véase AMBOS, “Art. 25 Individual”, cit. nota n 29 , nm. 18 y ss. con más referencias.

${ }^{78}$ En el mismo sentido AMBOS, “Art. 25 Individual”, cit. nota $n^{\circ} 29, \mathrm{~nm} .51$; conc. ESER, "Individual Criminal Responsibility", cit. nota 36, p. 819 con nota al pie 237.

${ }^{79}$ Supra nota ${ }^{\circ} 26$ y texto anexo.

${ }^{80}$ Hago mención aquí a anteriores análisis, supra nota $\mathrm{n}^{\circ} 26$, pp. 172-3, omitiendo las antiguas referencias y agregando algunas más recientes.

${ }^{81}$ Tadic Appeals Judgment, supra nota ${ }^{\circ}$ 26, para. 222.
} 
AMBOS, KAI. "El derecho penal internacional en la encrucijada: de la imposición ad hoc a un sistema universal basado en un tratado internacional".

categorías del JCE creada por la misma decisión y un análisis claro del sub-parágrafo (d). ${ }^{82}$ Mientras que la JCE I constituye, como se mencionara anteriormente, una forma de coautoría y por tanto, queda subsumida en el significado del artículo 25(3a) alternativa 2, las JCE II y III no están incluidas en el artículo 25(3d), por lo menos por dos razones. Primero, el sub-parágrafo (ii) del artículo 25(3d) requiere "conocimiento" respecto a la intención criminal del grupo, es decir, más que una mera previsibilidad, como requiere la JCE II y III. Segundo, si bien podría sostenerse que la JCE II y III están contenidas en el artículo 25(3d)(i), toda vez que el elemento subjetivo en este sub-parágrafo ("con el propósito de llevar a cabo la actividad o propósito delictivo del grupo...") no es incompatible con la previsibilidad, ${ }^{83}$ la contribución al crimen colectivo debe ser, en todo caso, intencional (art. 25(3d) $1^{\mathrm{a}}$ cláusula), es decir, que requiere más que una mera previsibilidad. ${ }^{84}$ Para la futura jurisprudencia de la CPI esto significa que la aplicación de la doctrina de la JCE III sobre la base del artículo 25 -y esta es la única base que tiene- supondría una violación de una lex stricta conforme el significado del artículo 22(2) $1^{\mathrm{a}}$ cláusula.

Con respecto a los crímenes, la aplicación del nullum crimen es bastante clara porque el artículo 22(1) limita la responsabilidad penal a una conducta que "en el momento en que tiene lugar" constituye "un crimen de la competencia de la Corte". Esto excluye los crímenes que no se encuentran en el Estatuto. ${ }^{85}$

El artículo 22(3), que conserva "la tipificación de una conducta como crimen de derecho internacional independientemente del presente Estatuto", no cambia esta situación ya que el Estatuto prevalecerá sobre esta disposición (art. 21(1): "En primer lugar...”) y sólo se aplicará de acuerdo con el artículo 15(2) del PIDCP y del artículo 7(2) del CEDH al derecho penal internacional aplicado por otros tribunales (nacionales e internacionales). ${ }^{86} \mathrm{Sin}$ embargo, podría haber una excepción en el caso de una declaración ad hoc retroactiva de un Estado de conformidad con el artículo 12(3). Con arreglo a esta disposición, un Estado podría aceptar la jurisdicción de la CPI con respecto a una situación específica, pero ¿podría darle un efecto retroactivo a esta declaración, por ejemplo, declarando que los crímenes de lesa humanidad son aplicables aunque se hubieran cometido con anterioridad a la entrada en vigor del Estatuto para ese Estado? La disposición sobre la jurisdicción temporal, artículo 11(2), parece confirmar esto en la última parte del parágrafo 2 , disponiendo que "a menos que éste haya hecho una declaración de conformidad con el párrafo 3 del artículo 12", es decir, haciendo en este caso una excepción a la regla general relativa a que "la Corte podrá ejercer su competencia únicamente con respecto a los crímenes cometidos después de la entrada en vigor del presente Estatuto" respecto de ese Estado (art. 11(2) primera parte). Por lo tanto, una lectura conjunta de todas estas disposiciones sugiere que el Estado puede, a través de una declaración expresa, permitir la aplicación retroactiva del Estatuto respecto de una situación presentada en los términos del artículo 12(3). Sin embargo, una interpretación teleológica demanda que este efecto retroactivo "situacional" no debe ser extendido más allá de la fecha de la entrada en vigencia del Estatuto $\left(1^{\circ}\right.$ de julio 2002, art. 126(1)), ya que de otra manera la regla general del nullum crimen, referida al Estatuto como un todo (arts. 11(1), 22 a 24), quedaría menoscabada. Además, toda vez que el Estatuto no existe como un instrumento legal efectivo antes de su entrada en vigor, no podría ser aplicable a situaciones ocurridas en ese período de tiempo.

\footnotetext{
${ }^{82}$ En este sentido es sorprendente que J. D. OHLIN, en "Three conceptual problems with the doctrine of Joint Criminal Enterprise", (2007) 5 JICJ 69, p. 77 se refiere al art. 25 sin mayores diferenciaciones, aunque es claro del siguiente texto (pp. 78 y ss.), que él considera que la JCE está incluida en el para. 3 (d).

${ }^{83}$ En este sentido OHLIN, "Three conceptual problems", cit. nota ${ }^{\circ}$ 82, p. 85.

${ }^{84}$ El argumento contrario de CASSESE, A., "The Proper Limits of Individual Responsibility Under the Doctrine of Joint Criminal Enterprise", (2007) 5 JICJ 109, p. 132, exigiendo una interpretación más extensa del término "intencional" ("requiring that the intent be referred to the common criminal plan, and, as such, may also embrace acts performed by one of the participants outside that criminal plan ...") entra en conflicto con el principio de legalidad, en particular con la prohibición de analogía prevista en el art. 22(2) del Estatuto CPI; lo mismo se aplica a su interpretación del término "conocimiento" del art. 25(3)(d)(ii) extendiéndolo a la "previsibilidad y tomando voluntariamente el riesgo". La contradicción entre la "intención" y la "previsibilidad" solo puede resolverse distinguiendo entre el objeto de referencia de la intención requerida en el art. 25(3)(d): mientras la participación concreta del participante a la conducta colectiva bien podría ser intencional, éste no actúa de forma intencional con respecto a los excesos, sino que éstos deben ser meramente "previsibles".

${ }^{85}$ Cfr. CATENACCI, M., Legalità e Tipicità del Reato Nello Statuto Della Corte Penale Internazionale (2003), pp. 187 y ss.; conc. BORSARI, R., Diritto Punitivo Sovranazionale, cit. nota n ${ }^{\circ} 76$, p. 289.

${ }^{86}$ BROOMHALL, B., “Art. 22 Nullum Crimen Sine Lege”, en TRIFFTERER, Commentary on the Rome Statute, cit. nota $n^{\circ} 29$, nm. 50-51.
} 
Un ejemplo concreto surge del juicio a Lubanga, y se refiere al crimen de reclutamiento forzoso de niños. La Sala de Cuestiones Preliminares debió aplicar el artículo 8(2b)(xxvi), toda vez que consideró el conflicto en la región de Ituri de la República Democrática del Congo (DRC en sus siglas en inglés) desde julio de 2002 hasta el 2 de junio de 2003, como uno de carácter internacional. ${ }^{87}$ Esta disposición criminaliza el reclutamiento de niños dentro de las "fuerzas armadas nacionales" -en contraste al artículo 8(2e)(vii)-, aplicable a los conflictos armados no internacionales, que se refieren a "fuerzas armadas o grupos". Como consecuencia, la SCP se enfrentó con la difícil cuestión de si el reclutamiento de niños dentro de un grupo no estatal rebelde o movimientos insurgentes, como las Forces Patriotiques pour la Libération de Congo (en adelante, FPLC), está subsumido dentro de este delito. Si bien el FPLC ciertamente califica como una fuerza armada, el término "nacional" puede restringir el alcance de la disposición a fuerzas armadas gubernamentales y ser, por lo tanto, inaplicable al reclutamiento dentro de una fuerza irregular como el FPLC. Guiada por el artículo 31 de la Convención de Viena sobre el Derecho de los Tratados, la SCP comienza su interpretación analizando el significado ordinario del término "nacional". ${ }^{88}$ Refiriéndose a varias sentencias del TPIY, la Sala sostiene que "nacionales" no significa necesariamente fuerzas armadas "gubernamentales". Sin embargo, en esas decisiones, el TPIY analizó la cuestión de si "nacional” en los términos del artículo 4(1) del IV Convenio de Ginebra podría ser interpretado como "étnico" o como "perteneciente al partido de la oposición", es decir, que estas sentencias fueron emitidas en un contexto totalmente diferente. Por lo tanto, es muy cuestionable que estas consideraciones puedan ser aplicadas sin más a la interpretación de "fuerzas armadas nacionales". ${ }^{89}$ Sin ninguna referencia a los travaux, la Sala sostiene además que los redactores del Estatuto pretendieron incluir en el artículo 8 del Estatuto una serie más amplia de conductas criminales cometidas en el contexto de un conflicto armado internacional. ${ }^{90}$ Sin embargo, esta afirmación se contradice con la historia de la redacción y no puede ser conciliada con el principio nullum crimen por las siguientes razones: Como correctamente sostiene la Sala, el artículo 8 (2b)(xxvi) está basado en el artículo 77 del Protocolo Adicional I (en adelante, PA I) del CG IV que obliga a los Estados miembros a tomar todas las medidas posibles para prevenir que los niños participen directamente en las hostilidades. La Sala sostiene que el PA I no está limitado a las fuerzas armadas gubernamentales. ${ }^{91}$ En el mismo sentido, la propuesta original del Comité Preparatorio preveía el reclutamiento de niños dentro de las fuerzas armadas; solo después se agregó el término "nacional". Esto se hizo para dar respuesta a las preocupaciones de varios Estados árabes, especialmente El Líbano, que temía que la primera versión pudiera cubrir las fuerzas de Hezbollah. Más aún, el mero hecho de su incorporación muestra la intención de los redactores de limitar la aplicación de esta disposición sólo a las fuerzas armadas del Estado. ${ }^{92}$ Precisamente por esta razón esta disposición fue criticada por varios grupos de derechos humanos que objetaban que los movimientos rebeldes serían excluidos. ${ }^{93}$

De acuerdo a estos antecedentes, no es sorprendente que la Sala no tuviera otra opción que la de sostener una interpretación extensiva de la disposición en discusión tomando en cuenta "consideraciones humanitarias y el sentido común." 94 Según la Sala un resultado diferente sería contrario al objeto y fin del Estatuto de la Corte, que no es otro que el de asegurar que los crímenes más graves de trascendencia para la comunidad internacional en su conjunto no queden sin castigo. ${ }^{95}$ Sin embargo, estas consideraciones -convincentes como son desde el punto de vista de una política general- no pueden eximir a la Sala de la interpretación correcta y exacta de las disposiciones correspondientes. El artículo 21(1a) obliga a la Sala, en forma explícita, a aplicar en primer lugar el Estatuto y no la Convención de Viena que, de hecho, es un mero instrumento

\footnotetext{
${ }^{87}$ Prosecutor v. Lubanga, supra nota 28, paras. 209, 220.

${ }^{88}$ Ibid., paras. $276,277-80$.

89 BEKOU, O., "Prosecutor v. Thomas Lubanga Dyilo - Decision on the Confirmation of Charges", (2008) 8 Human Rights Law Review 348, p. 353.

${ }_{90}$ Prosecutor v. Lubanga, supra nota ${ }^{\circ} 28$, para. 284.

${ }^{91} \mathrm{Ibid}$., para. 272. Véase para responder a la pregunta de si el FPLC podría calificar como grupo armado en los términos del Protocolo Adicional I, BEKOU, "Prosecutor v. Thomas", cit. nota ${ }^{\circ}$ 89, p. 352.

92 VON HEBEL. H., ROBINSON, D., "Crimes Within the Jurisdiction of the Court", en LEE, R. S., (ed.), The International Criminal Court - The Making of the Rome Statute (1998), 79, p. 118; On the Record (OTR) ICC, Vol.1 (11), 2 de Julio de 1998, p. 3; OTR ICC, Vol 1 (23), 27 de julio (art. 1) 1998, p. 4. Véase también DE BECO, G., "War Crimes in International Versus Non-International Armed Conflicts: 'New Wine in Old Wineskins?", (2008) 8 ICLR 326, p. 328; BEKOU, "Prosecutor v. Thomas", cit. nota ${ }^{\circ} 89$, p. 353 y ss.

${ }^{93}$ Véase OTR ICC, Vol. 1 (11), 2 de Julio de 1998, p. 3; Amnistía Internacional, Preliminary Report to Membership on Outcome of the Rome Diplomatic Conference to Establish a Permanent International Criminal Court and Proposed Follow-Up Action for Next Two Years (24 de julio de 1998), p. 4

${ }^{94}$ Prosecutor v. Lubanga, supra nota ${ }^{\circ} 28$, para. 284.

${ }^{95}$ Ibid., para. 281.
} 
AMBOS, KAI. "El derecho penal internacional en la encrucijada: de la imposición ad hoc a un sistema universal basado en un tratado internacional".

de interpretación. Si el Estatuto utiliza un término como "nacional" y éste fue incluido expresando la clara intención de los redactores, la Sala debe aceptar este término e interpretarlo. No se puede hacer caso omiso de una redacción clara recurriendo al objeto y fin del Estatuto. En caso de ambigüedad, el término debe ser interpretado a favor del sospechoso o acusado (art. 22(2) cláusula 2 ).

Aún se podría sostener que la disposición pudiese ser extendida a grupos armados no gubernamentales, ${ }^{96}$ sin embargo, ese argumento debería estar basado en una interpretación conforme a las reglas generales de interpretación, y no sólo sobre la base de consideraciones humanitarias y sentido común. En consecuencia, la extensión de la disposición realizada por la Sala a todas las fuerzas armadas ignora la decisión legislativa de los Estados miembros y viola la lex stricta del artículo 22(2) de la cláusula $1 .^{97}$

\section{Conclusión}

Este tour d'horizon desde la imposición (vertical) del sistema ad hoc de la justicia penal internacional al régimen universal (horizontal) de la CPI, muestra que hay varias cuestiones sin resolver y una necesidad creciente de mayor reflexión e investigación. El artículo no pretende dar ninguna respuesta definitiva a las acuciantes cuestiones legales discutidas, sino que la intención fue la de primeramente identificarlas y crear un necesario estado de alerta. En cualquier caso parece claro que la "crisis de identidad del derecho penal internacional" "98 sólo puede ser resuelta si el derecho penal internacional se establece como una disciplina por propio derecho y sobre la base de los principios fundamentales del derecho penal, inherentes a cualquier sistema legal justo y liberal. ${ }^{99}$

En este contexto, vale la pena echar una mirada a los fundamentos metodológicos o puntos de partida del debate de la doctrina internacional en general y de los sistemas legales penales subyacentes en particular. Un académico chileno publicó recientemente un interesante trabajo ${ }^{100}$ en este sentido, distinguiendo entre las diferencias externas e internas de los sistemas legales más importantes, es decir, el common law y los ordenamientos penales influenciados por el derecho alemán. ${ }^{101}$ Con respecto a las diferencias externas, se refiere a las diferentes construcciones o sistemas de crimen utilizados en los dos sistemas (la dicotomía delito - defensa del common law versus la distinción en tres o cuatro niveles de los elementos del delito, la antijuricidad y la culpabilidad de los sistemas germánicos) ${ }^{102} \mathrm{y}$, concluye que a pesar de estas diferencias los resultados son a menudo idénticos o similares. ${ }^{103}$ En cuanto a las diferencias internas, este autor identifica distintos abordajes metodológicos y filosóficos en ambos sistemas y distingue el abordaje sistemático e idealista del derecho continental influenciado por el derecho alemán, con la idea de un derecho penal que contiene el propósito en sí mismo (Kant, Hegel) del abordaje anglosajón pragmático y utilitario con la idea de disuasión y protección de la sociedad (Beccaria, Bentham). ${ }^{104}$ Dada, por una parte, la aceptación general de los propósitos preventivos (utilitarios) de la pena en la corriente de pensamiento alemán más importante ${ }^{105}$ y la recepción de los elementos Kantianos en el derecho inglés, ${ }^{106}$ y, por otra parte, la influencia de otros factores en el armado del futuro concepto de crimen en el derecho penal internacional (tales como la formación

\footnotetext{
${ }^{96}$ Por ejemplo, Amnistía Internacional, supra nota n 93, p. 4. Para una interpretación restrictiva, DE BECO, "War Crimes", supra nota n ${ }^{\circ}$ 92, p. 328; BEKOU, "Prosecutor v. Thomas", cit. nota n 89, p. 354.

${ }^{97}$ Véase también DE BECO, "War Crimes", supra nota n ${ }^{\circ}$ 92, p. 328.

98 Véase recientemente ROBINSON, D., "The identity crisis of International Criminal Law", (2008) 21 LJIL 925 criticando, inter alia, la influencia expansiva del derecho internacional de los derechos humanos y el derecho humanitario en el derecho penal internacional ampliando sus principios de responsabilidad (929, 961 y passim). Véase id., "The two liberalisms of international criminal law", en STAHN, C., VAN DEN HERIK, L., (eds.), Future perspectives on international criminal justice, The Hague: T.M.C. Asser Press, 2010, pp. 115-160.

${ }^{99}$ Véase mi intento previo respecto de las reglas generales de atribución, en AMBOS, Kai, "Remarks on the general part of International Criminal Law" (2006), 4 JICJ 660 (en castellano en: AMBOS, Kai, Principios e imputación en el derecho penal internacional. Barcelona: Atelier, 2008, pp. 13 y ss.).

${ }_{100}$ MATUS, Jean Pierre, La Transformación de la Teoría del Delito en el Derecho Penal Internacional, Barcelona: Atelier, 2008.

${ }^{101}$ Matus distingue entre el common law y el Strafrechtswissenschaft alemán porque considera que es la fuerza decisiva dentro del sistema continental (civil law, Roman-Germanic) (ibid., p. 27 y ss., 55 y ss.).

${ }^{102}$ Para un análisis más profundo, véase AMBOS, “Toward a Universal System”, cit. nota n 53, pp. 2648 y ss.

${ }^{103}$ MATUS, La Transformación, cit. nota ${ }^{\circ} 100$, pp. 27 y ss. deconstruyendo las diferencias en los cuatro niveles y refiriéndose, inter alia, a la cuestión de la coacción en la sentencia Erdemovic (supra nota $n^{\circ} 22$ y texto anexo).

${ }_{105}^{104}$ MATUS, La Transformación, cit. nota ${ }^{\circ} 100$, pp. 55 y ss., 65 y ss.

${ }_{105}$ Cfr. ROXIN, Claus, Strafrecht Allgemeiner Teil, $4^{\text {th }}$ ed. (2006), $\S 19$, espec. nm. 18 y ss. contiene más referencias.

${ }^{106}$ MATUS, La Transformación, cit. nota ${ }^{\circ} 100$, pp. 84 y ss.
} 
jurídica del personal de la CPI, el dominio del idioma inglés, el input doctrinario de ciertos sistemas), ${ }^{107}$ tal dicotomía es en nuestros días ciertamente una exageración. No obstante, esto de ninguna manera disminuye la utilidad de una investigación de las raíces y tradiciones de nuestros abordajes del delito y castigo para una mejor comprensión del futuro desarrollo del derecho penal internacional. Claramente ese enfoque debe ser complementado por conceptos no occidentales del crimen y del castigo, por ejemplo del derecho Islámico, ${ }^{108}$ toda vez que un enfoque puramente occidental carece de legitimidad para establecer y desarrollar un sistema universal. Sin embargo, para que estas perspectivas no occidentales sean escuchadas y comprendidas es necesario, en primer término, que los académicos no occidentales se den a conocer activamente y las presenten ${ }^{109} \mathrm{y}$, en segundo término, que los académicos occidentales estén preparados para escuchar y discutir con ellos.

\section{BIBLIOGRAFIA}

\section{A. Libros.}

AHLBRECHT, Heiko, Geschichte der Völkerrechtlichen Strafgerichtsbarkeit im 20. Jahrhundert, Baden-Baden, 1999.

AMBOS, Kai, La Parte General del Derecho Penal Internacional. Bases para una elaboración dogmática, Montevideo, Konrad Adenauer Stiftung, 2005 (también Bogotá: Temis, 2006) [Versión original en alemán: Der Allgemeine Teil des Völkerstrafrechts. Ansätze einer Dogmatisierung, Berlin: Duncker \& Humblot, 2. Aufl. 2004.]

AMBOS, Kai/OTHMANN, Mophamed (eds.), New Approaches in International Criminal Justice: Kosovo, East Timor, Sierra Leone and Cambodia, 2003.

ASHWORTH, Andrew, Principles of Criminal Law, Oxford: Oxford University Press, 6a. ed., 2009.

BADAR, Mohamed, The Concept of Mens Rea in International Criminal Law, 2008.

BAGARIC, Mirko/ARENSON, Ken J., Criminal Laws in Australia, 2007.

BASSIOUNI, M. Cherif, The legislative History of the ICC, vol. 2, 2005.

BORSARI, Riccardo, Diritto Punitivo Sovranazionale come Sistema, 2007.

BROWNLIE, Ian, Principles of Public International Law, 2003.

CASSESE, Antonio, International Criminal Law, $2^{\mathrm{a}}$ ed., 2008.

CATENACCI, Mauro, Legalità e Tipicità del Reato Nello Statuto Della Corte Penale Internazionale, 2003.

DAMA KA, Mirjan R., Two Faces of Justice and State Authority, 1986.

FAIRCHILD, Erika S./DAMMER, Harry R., Comparative Criminal Justice Systems, 2a. ed, Belmont: Wadsworth Publishing Company, 2001.

FLETCHER, George P., Rethinking Criminal Law, 1978, (reimpresión 2000).

HEINSCH, Robert, Die Weiterentwicklung des Humanitären Völkerrechts Durch die Strafgerichtshöfe für das Ehemalige Jugoslawien und Ruanda, 2007.

HOFSTETTER, Elias, Das Verfahrensrecht Internationales Strafgerichte Zwischen Common Law und Civil Law, 2005.

JAHRREIß, Hermann, Der Bruch des Zwischenstaatlichen Friedens und Seine Strafbarkeit. Plädoyer vor dem Internationalen Militärgerichtshof zu Nürnberg, 1946.

JESCHECK, Hans H., Die Verantwortlichkeit der Staatsorgane nach Völkerstrafrecht, 1952.

LaFAVE, Wayne R., Principles of Criminal Law, 2003.

MATUS, Jean Pierre, La Transformación de la Teoría del Delito en el Derecho Penal Internacional, Barcelona: Atelier, 2008.

METTRAUX, Guenaël, International crimes and the ad hoc tribunals, 2005.

MINEAR, Richard H., Victors' justice: The Tokyo War Crimes Trial, 1971.

NÍ CHOILEÁIN, Cecilia, Criminal Law, 2006.

\footnotetext{
${ }^{107}$ Véase también ibid., pp. 91 y ss.

${ }^{108} \mathrm{Cfr}$. algunos trabajos recientes realizados por una nueva generación de académicos árabes, véase BADAR, M. E., The Concept of Mens Rea in International Criminal Law (2008); MAGED, A., "Arab and Islamic Shari'a Perspectives on the Current System of International Criminal Justice", (2008) 8 ICLR 477; para una perspectiva occidental véase PETERS, R., Crime and Punishment in Islamic Law: Theory and Practice from the Sixteenth to the Twenty-First Century (2005); con respecto a los prisioneros de guerra véase EL ZEIDY, M, MURPHY, R., "Islamic Law on Prisoners of War and its Relationship with International Humanitarian Law", (2004) 14 The Italian Yearbook of Italian Law 53.

${ }^{109}$ Por ejemplo, como el realizado por el Dr. Elewa Badar durante su intervención sobre "Shari'a and the jurisdiction of the ICC" en el Tenth Salzburg Law School on International Criminal Law el 8 de agosto de 2008.
} 
AMBOS, KAI. "El derecho penal internacional en la encrucijada: de la imposición ad hoc a un sistema universal basado en un tratado internacional".

PETERS, Rudolph, Crime and Punishment in Islamic Law: Theory and Practice from the Sixteenth to the Twenty-First Century, Cambridge, UK and New York: Cambridge University Press, 2005.

RAIMONDO, Fabian, General Principles of Law in the Decisions of International Criminal Courts and Tribunals, 2007.

ROMANO, Cesare. P.R. (ed.), Internationalized Criminal Courts and Tribunals: Sierra Leone, East Timor, Kosovo and Cambodia, 2004.

ROXIN, Claus, Strafrecht-Allgemeiner Teil. Grundlagen. Der Aufbau der Verbrechenslehre, t. I, 4th ed., 2006.

ROXIN, Claus, Täterschaft und Tatherrschaft, 2006.

SATZGER, Helmut, Internationales und Europäisches Strafrecht, 4ta ed. 2010.

SCHABAS, William A., The UN International Criminal Tribunals: The Former Yugoslavia, Rwanda and Sierra Leone, 2006.

SCHARF, Michael P./NEWTON, Michael A., Enemy of the State, 2008.

STUART, Don, Canadian Criminal Law, 2001.

TOTANI, Yuma, The Tokyo War Crimes Trial: The Pursuit of Justice in the Wake of World War II, 2008.

VON BRAUN, Leonie, Internationalisierte Strafgerichte, 2008.

VON CLAUSEWITZ, Carl, Vom Kriege, Vol. 1 (1832), para 24 (transl. J.J. Graham, On War (1873), disponible en: http://www.clausewitz.com/CWZHOME/VomKriege/VKTOC2.htm

WERLE, Gerhard, Völkerstrafrecht, Tübingen: Mohr Siebeck, 2. ed. 2007.

ZAHAR, Alexander / SLUITER, Göran, International Criminal Law, 2008.

ZOLO, Danilo, La justicia de los vencedores. De Nuremberg a Bagdad, 2006.

\section{B. Capítulos en Libros o en revistas especializadas.}

AHLBRECHT, Heiko,"Europäischer Strafrechtsraum: Ein Albtraum?”, Zeitschrift für Rechtspolitik, 2004, pp. 1 y ss., esp. p. 3.

AMBOS, Kai, "Other grounds for Excluding Criminal Responsibility”, en CASSESE, Antonio; GAETA, Paola; JONES, John R.W.D., The Rome Statute of the International Criminal Court: A Commentary, Vol. I, 2002, 1003, pp. 1042 y ss.

'International Criminal Procedure: 'Adversarial', 'Inquisitorial' or 'Mixed'?”, 2003, 3 International Criminal Law Review 1, pp. 1-37. (en castellano publicado en Derecho Penal Contemporáneo, Legis, Colombia, No. 7, Abril-Junio 2004, 556; Revista General de Derecho Procesal IUSTEL, núm. 3, 2004, htpp://www.iustel.com/revistas; Revista Brasileira de Ciências Criminais, Instituto Brasileiro de Ciências Criminais, Sao Paulo, 57, novembre-dezembro 2005, 159-211).

" "Remarks on the General Part of International Criminal Law", 4 Journal of International Criminal Justice 660, 2006, pp. 667-68.

" "Nulla Poena Sine Lege in International Criminal Law", en HAVEMAN, Roelof; OLUSANYA, Olaoluwa, (eds.), Sentencing and Sanctioning in Supranational Criminal Law, 2006, pp. 17 a 21 (en castellano por ej. en Ciencias Penales, Costa Rica, no. 26, 2009, 31-44).

"The Structure of International Criminal Procedure: 'Adversarial', 'Inquisitorial' or 'Mixed'?', en BOHLANDER, Michael (ed.), International Criminal Justice: A Critical Analysis of Institutions and Procedures, 2007, pp. 429-503.

"Joint Criminal Enterprise and Command Responsibility", 5 Journal of International Criminal Justice 159, 2007, p. 170 (en castellano en Revista de Derecho Penal y Criminología, Universidad Nacional de Educación a Distancia, Facultad de Derecho, 2da Epoca, t. 19, enero 2007, 39-78).

Toward a universal system of crime: Comments of George Fletcher's Grammar of Criminal Law, 28 Cardozo Law Review 2647, 2007, p. 2648 y ss.

"Art. 25 Individual Criminal Responsibility”, en TRIFFTERER, Otto (ed.), Commentary on the Rome Statute of the International Criminal Court, 2008, impresión especial, mn. 7 y ss.

Amicus Curiae for the Extraordinary Chambers in the Courts of Cambodia concerning Crimina, 1 Case File No. 001/18-07-2007-ECCC/OCIJ (PTC 02), 27 de octubre de 2008, pp. 13 y ss., la cual se halla disponible en http://www.eccc.gov.kh/english/court_doc.list.aspx.

, "Critical issues in the Bemba confirmation decision", Leiden Journal of International Law, 22, 2009, p. 718. 
"Witness Proofing before the ICC: Neither Legally Admissible Nor Necessary”, en STAHN, Carsten SLUITER Göran (eds.), The Emerging Practice of the International Criminal Court, 2009, p. 599 (en castellano en: AMBOS, Kai; DE HOYOS SANCHO, Montserrat, Cuestiones esenciales en la jurisprudencia de la Corte Penal Internacional, Granada: Comares, 2008, pp. 1-22);

,"«Kai Witness Proofing» before the ICC. A reply to Karemaker, Taylor and Pittman”, Leiden Journal of International Law, 21, 2008, pp. 911.

"El Derecho Penal Internacional en la encrucijada: de la imposición AdHoc a un sistema universal basado en un Tratado Internacional" en STAHN, Carsten; VAN DEN HERIK, Larissa (eds.), Future perspectives on international criminal justice, The Hague: T.M.C. Asser Press, 2010, pp. 161-177. (Traducción del inglés realizada por Carolina Anello con asistencia de Natalia Luterstein (ambas Universidad de Buenos Aires).

BADAR, Mohamed E., “'Just Convict Everyone!'- Joint Perpetration: From Tadic to Stakic and Back Again”, en 6 International Criminal Law Review 293, 2006,

BIDDISS, Michael, "Victors' Justice? The Nuremberg Tribunal”, 1995, 45 History Today, 40.

BADAR, Elewa, "Shari' $a$ and the jurisdiction of the ICC" en el Tenth Salzburg Law School on International Criminal Law el 8 de agosto de 2008.

BEKOU, Olympia, "Prosecutor v. Thomas Lubanga Dyilo - Decision on the Confirmation of Charges", 8 Human Rights Law Review 348, 2008, p. 353.

CASSESE, Antonio, "The Proper Limits of Individual Responsibility Under the Doctrine of Joint Criminal Enterprise”, 2007, 5 Journal of International Criminal Justice 109, p. 132,

CRYER, Robert; FRIMAN, Håkan; ROBINSON, Darry; WILMSHURST, Elizabeth, An introduction to international criminal law and procedure, 2007.

DE BECO, Gathier, "War Crimes in International Versus Non-International Armed Conflicts: 'New Wine in Old Wineskins?',', 2008, 8 International Criminal Law Review 326, p. 328.

DE BERTODANO, Sylvia, "Were there more acceptable alternatives to the Iraqi High Tribunal?, 2007, 5 Journal of International Criminal Justice 294.

DOUGHERTY, Beth, “Victims' Justice, Victors' Justice: Iraq's flawed Tribunal”, en 1 Middle East Policy 61, 2004.

DUTTWILLER, Michael, "Liability for Omission in ICL”, en 6 International Criminal Law Review 1, 2006.

EL ZEIDY Mohamed; MURPHY, Ray, "Islamic Law on Prisoners of War and its Relationship with International Humanitarian Law”, 2004, 14 The Italian Yearbook of Italian Law 53.

ESER, Albin, "Auf dem Weg zu einem internationalen Strafgerichtshof etc.", en COURAKIS, NESTOR (ed.), Die Strafrechtswissenschaft im 21. Jahrhundert: Festschrift für Dionysios Spinellis, 2001, 339, p. 365.

FERNÁNDEZ DE GURMENDI, S., "The Elaboration of the Rules of Procedure and Evidence”, en LEE, Roy S. (ed.), ICC: Elements of Crimes and Rules of Procedure and Evidence, 2001, 235, p. 251.

FRIMAN, Håkan, "The Rules of Procedure and Evidence in the Investigative Stage”, en FISCHER, Horst; KRESS, Claus; LÜDER, Sascha R. (eds.), International and National Prosecution of Crimes under International Law, 2001, pp. 214, 217.

GORDLEY, James, "Common Law and Civil Law: Eine Uberholte Unterscheidung”, 1 Zeitschrift für Europäisches Privatrecht, 498, 1993, p. 498-518.

VITZTHUM, Wolfgang G., "Begriff, Geschichte und Quellen des Völkerrechts”, en VITZTHUM, Wolfgang G.(ed.), Völkerrecht, 2004, pp. 1 a 64, números marginales (mn.) pp. 131-3

GREEN, Leslie C., "The maxim nullum crimen sine lege and the Eichmann Trial", 38 The British Year Book of International Law 457, 1967, p. 471

HARRIS, Whitney R., "International Human Rights and the Nuremberg Judgement”, 12 Santa Clara Lawyer 209, 1972, pp. 216-17

HEISS, Helmut, "Hierarchische Rechtskreiseinteilung, Von der Rechtskreislehre zur Typologie der Rechtskulturen?", Zeitschrift für vergleichende Rechtswissenschaft 100, 2001, p. 396424.

HOLLWEG, Carsten, "Das Neue Internationale Tribunal der UNO und der Jugoslawienkonflikt”, 48 Juristenzeitung 980, 1993, p. 985.

HUSA, Jaakko, "Classification of Legal Families Today Is It Time for a Memorial Hymn?", en Revue Internationale de Droit Comparé 56, 2004, p. 11-38.

KAREMAKER, Ruben; TAYLOR III, Don B.; PITTMANT, T. Wayde, "Witness proofing in International Criminal Tribunals: Response to Ambos”, 2008, 21 Leiden Journal of International Law 917. 
AMBOS, KAI. "El derecho penal internacional en la encrucijada: de la imposición ad hoc a un sistema universal basado en un tratado internacional".

," Witness Proofing in International Criminal Tribunals: A Critical Analysis of Widening Procedural Divergence”, 21 Leiden Journal of International Law 683, 2008

KELSEN, Hans, "Will the Judgment in the Nuremberg Trial Constitute a Precedent in International Law?”, 1947, 1 The International Law Quarterly 153, pp. 164-5. Reimpreso en METTRAUX, Guénaël (ed.), Perspectives on the Nuremberg trial, 2008, p. 274.

KREß, Claus, "Claus Roxins Lehre von der Organisationsherrschaft und das Völkerstrafrecht", en Goldthammer's Archiv für Strafrecht 304, 2006, p. 307.

LATERNSER, Hans, "Looking Back at the Nuremberg Trials with Special Consideration of the Process Against Military Leaders”, en 8 Whittier Law Review 557, 1986, p. 572

LIPPMAN, Matthew, “Nuremberg: Forty Years Later”, 7 Connecticut Journal of International Law 1, 1991, pp. 44-5.

MAGED, Adel, "Arab and Islamic Shari'a Perspectives on the Current System of International Criminal Justice”, 8 International Criminal Law Review 477, 2008.

McINTYRE, D. G., "The Nuremberg Trials”, 24 Pittsburgh Law Journal 73, 1962, pp. 97

MEERNIK, James, "Victor's Justice or the Law? Judging and Punishing at the International Tribunal for the Former Yugoslavia”, 2003, 47 Journal of Conflict Resolution 140.

MODOLELL GONZÁLEZ, Juan, "Problemas de Autoría en la Sentencia del 29 de Enero de 2007 de la Sala de Cuestiones Preliminares I de la Corte Penal Internacional (Confirmación de Cargos Contra Thomas Lubanga Dyilo)", en DE HOYOS SANCHO, Montserrat (eds.), Cuestiones Esenciales en la Jurisprudencia de la Corte Penal Internacional, 2008, p. 91, pp. 93 y ss.

OHLIN, Jen, "Three conceptual problems with the doctrine of Joint Criminal Enterprise", 5 Journal of International Criminal Justice 69, 2007, pp. 77 y ss

PEARL, Elizabeth L., "Punishing Balkan War Criminals: Could the End to Yugoslavia provide an End to Victors' Justice?”, 1993, 30 American Criminal Law Review 1373.

PESKIN, Victor, "Beyond Victor's Justice? The Challenge of Prosecuting the Winners at the International Tribunal for the Former Yugoslavia and Rwanda”, 2005, 4 Journal of Human Rights 213.

RADBRUCH, Gustav, Zur Diskussion über die Verbrechen gegen die Menschlichkeit”, 1947, 2 Süddeutsche Juristenzeitung columna 131, columna 135.

ROBINSON, Darryl, "The two liberalisms of international criminal law”, en STAHN, Carsten; VAN DEN HERIK, Larissa (eds.), Future perspectives on international criminal justice, The Hague: T.M.C. Asser Press, 2010, pp. 115-160.

ROBINSON, Darryl, “The identity crisis of International Criminal Law”, 21 Leiden Journal of International Law 925, 2008.

ROJO, Enrique C., "The Role of Fair Trial Considerations in the Complementarity Regime of the ICC: From "No Peace without Justice" to "No Peace with Victors' Justice?",", en 18 Leiden Journal of International Law 829, 2005.

SCHARF, Michael P., "The Iraqi High Tribunal: A Viable Experiment in International Justice?”, en 5 Journal of International Criminal Justice, 2007, p. 258;

SCHEUERMANN, Leslie, 'Victors Justice? The Lessons of Nuremberg Applied to the Trial of Saddam Hussein”, 2006, 15 Tulane Journal of International and Comparative Law 291.

SISSONS, Mirand; BASSIN, Ari S., "Was the Dujail Trial Fair?”, en 5 Journal of International Criminal Justice 272, 2007.

SMITH, T. H., “Judicial Law Making in the Criminal Law”, en 100 Law Quarterly Review 46, 1984.

SPALHOLZ, H. M., "Saddam Hussein and the IST on Trial: The Case for the ICC", en 13 Buffalo Human Rights Law Review 255, 2007.

TRÜG, Gerson, "Erkenntnisse aus der Untersuchung des US-amerikanischen plea bargainingSystems for den Deutschen Absprachendiskurs", 120 Zeitschrift für die Gesamte Strafrechtswissenschaft 331, 2008, pp. 347, 364 y ss., 367 y ss.

VON HEBEL, Hermann; DARRYL, Robinson, "Crimes Within the Jurisdiction of the Court", en LEE, Roy S. (ed.), The International Criminal Court - The Making of the Rome Statute, 1998, 79, p. 118.

WEIGEND, Thomas, Intent, Mistake of Law, and Co-Perpetration in the Lubanga Decision on Confirmation of Charges", 2008, 6 Journal of International Criminal Justice 471, pp. 478 y ss.

WERLE, Gerhard, "Individual Criminal Responsibility in Article 25 ICC Statute”, 5 Journal of International Criminal Justice 953, 2007, pp. 961-2.

WRINGE, Bill, "Why Punish War Crimes? Victors Justice and Expressive Justifications of Punishment”, 25 Law and Philosophy 159, 2006. 


\section{Otros documentos.}

Amnistía Internacional, Preliminary Report to Membership on Outcome of the Rome Diplomatic Conference to Establish a Permanent International Criminal Court and Proposed FollowUp Action for Next Two Years (24 de julio de 1998), p. 4

Comisión de Derecho, " $10^{\text {th }}$ Programme of Law Reform" at http://www.lawcom.gov.uk/docs/lc311.pdf.

Estatuto de la TPIY, UN Doc. S/Res/827 (1993).

Estatuto del TPIR, UN Doc. S/RES/955 (1994).

Estatuto del Tribunal Especial para el Líbano, Anexo al UN Doc. S/RES/1757 (2007).

$33^{\circ}$ Informe Anual de la Comisión de Derecho, disponible en http://www.lawcom.gov.uk/docs/lc258.pdf

Resolución 808 (1993) del Consejo de Seguridad, UN Doc. S/25704, 3 de mayo de 1993 y Corrigendum S/25704/Corr.1, 30 de Julio de 1993

Tratado de Renuncia a la Guerra (Pacto Briand - Kellog)

\section{Jurisprudencia.}

\section{1) Corte Penal Internacional}

Prosecutor v. Al Bashir, Decision on the Prosecutor's application for a warrant of arrest against Omar Hassan Ahmad Al Bashir, 4 de marzo de 2009 (ICC-02/05-01/09-3).

Prosecutor v. Germain Katanga and Mathieu Ngudjolo Chui, Decision on the confirmation of charges, Case No. ICC-01/04-01/07, 30 de septiembre de 2008, para. 480 y ss.

Prosecutor v. Jean-Pierre Bemba Gombo, ICC 01/05-01/08, del 15 de junio de 2009,

Prosecutor v. Katanga, Decision on the confirmation of charges, Case No. ICC-01/04-01/07-, del 30 de septiembre de 2008,

Prosecutor v. Thomas Lubanga Dyilo, Decision on the Practices of Witness Familiarisation and Witness Proofing, Case No. ICC-01/04-01/06, 8 de noviembre de 2006, para. 18 y ss., 28 y ss.)

Prosecutor v. Thomas Lubanga Dyilo, Decision on the Confirmation of Charges, Case No. ICC01/04-01/06(-803), de 29 de enero de 2007, para. 342,

Prosecutor v. Thomas Lubanga Dyilo, Prosecution Submissions Regarding the Subjects that Require Early Determination: Procedures to be Adopted for Instructing Expert Witnesses, Witness Familiarization and Witness Proofing, Case No. ICC-01/04-01/06-952, 12 de septiembre de 2007, para. 14

Prosecutor v. Thomas Lubanga Dyilo, Decision Regarding the Practices Used to Prepare and Familiarise Witnesses for Giving Testimony at Trial, Case No. ICC-01/04-01/06, 30 de noviembre 2007, para. 44.

\section{2) Resoluciones de otros Tribunales Internacionales.}

Prosecutor v. Delalic et al., Appeal Judgment, Case No. IT-96-21-A, 20 de febrero de 2001, paras. 342-3, 376.

Prosecutor v. Karemera et al., Decision on Interlocutory Appeal Regarding Witness Proofing, Case No. ICTR-98-44-AR73.8, 11 de mayo de 2007, para. 9 y ss.;

Prosecutor v. Kordic and Cerkez, Judgment, Case No. IT-95-14/2-T, 26 de febrero de 2001, paras. 375-6;

Prosecutor v. Limaj et al., Decision on the Defence Motion on Prosecution Practice of Proofing Witnesses, Case No. IT-03-66-T, 10 de diciembre de 2004, p. 2

Prosecutor v. Milutinovic et al., Decision on Ojdanic Motion to Prohibit Witness Proofing, Case No. IT-05-87-T, 12 de diciembre de 2006, para. 15

Prosecutor v. Musema, Judgment, Case No. ICTR-96-13-A, 27 de enero de 2000, para. 123

Prosecutor v. Sesay et al., Case Decision on the Gbao and Sesay Joint Application for the Exclusion of the Testimony of Witness, No. SCSL-04-I5-T, TF1-141, 26 de octubre de 2005, para. 33

Prosecutor v. Stakic, Trial Judgement, Case No. IT-97-24, del 31 de julio de 2003, para. 440

Prosecutor v. Stakic, Appeal Judgement, No. IT-97-24-A, del 22 de marzo de 2006, para 62.

Prosecutor v. Tadic, Appeal Judgement, Case No. IT-94-1, del 15 de julio de 1999, paras. 185 y ss.

Prosecutor v. Vasiljevic Judgment, Case No. IT-98-32-T, 29 November 2002, párrafo 193. 
AMBOS, KAI. "El derecho penal internacional en la encrucijada: de la imposición ad hoc a un sistema universal basado en un tratado internacional".

\section{3) Resoluciones de Tribunales Nacionales.}

Attorney General v. Eichmann, Judgment of the Jerusalem District Court, Case No. 40/61, 12 de diciembre de 1961, (1968) 36 International Law Reports, pp. 236-7, para. 197.

Cámara Nacional de Apelaciones en lo Criminal y Correccional de la Capital, 9 de diciembre de 1985, 309-I/II, Colección Oficial de Fallos de la Corte Suprema de Justicia de la Nación, Fallos: 33: 1657, pp. 1601-2. (Argentina)

Knuller v. DPP, House of Lords, Judgment of 14 June 1971, AC 1973, 435

Lochner v. New York, 198 US 45, p. 76 ,1905, Voto disidente del Juez Holmes, disponible en: http://supct.law.cornell.edu/supct/html/historics/USSC CR 01980045 ZS.html.

$R$ v. R, House of Lords, Judgment of 23 October 1991, AC 1992, 599 y M. Giles, "Judicial LawMaking in the Criminal Courts: The Case of Marital Rape", (1992) Crim. L. Rev. 407.

Shaw v. Director of Public Prosecutions, House of Lords, Judgment of 4 May 1961, Appeal Cases 1962, 220. 